\title{
Hipótese amiloide e o tratamento da doença de Alzheimer: revisão dos estudos clínicos realizados
}

\author{
Eslen Delanogare ${ }^{\mathrm{a}, *}$, Douglas Flores ${ }^{\mathrm{b}}$, Raul Marin de Souza ${ }^{\mathrm{a}}$, \\ Letícia de Souza ${ }^{a}$, Eduardo Luiz Gasnhar Moreira ${ }^{\mathrm{a}, \mathrm{c}}$ \\ ${ }^{a}$ Programa de Pós-Graduação em Neurociências, Neuroscience Coworking Lab, Universidade Federal de Santa \\ Catarina, Florianópolis, SC, Brasil \\ ${ }^{\text {b} P r o g r a m a ~ d e ~ P o ́ s-G r a d u a c ̧ a ̃ o ~ e m ~ P s i c o l o g i a ~ S o c i a l, ~ I n s t i t u t o ~ d e ~ P s i c o l o g i a, ~ U n i v e r s i d a d e ~ d e ~ S a ̃ o ~ P a u l o, ~ S a ̃ o ~ P a u l o, ~}$ \\ SP, Brasil \\ ${ }^{c}$ Departamento de Ciências Fisiológicas, Universidade Federal de Santa Catarina, Florianópolis, SC, Brasil
}

\section{Histórico do Artigo Recebido em: $16 / 10 / 2018$ \\ Aceito em: \\ $18 / 12 / 2018$ \\ Palavras-Chave: \\ Doença de Alzheimer; \\ Doenças \\ neurodegenerativas; \\ Ensaios clínicos. \\ Pesquisa translacional.}

Keywords:

Alzheimer's disease; Neurodegenerative diseases; Clinical studies; Translational research.

\begin{abstract}
RESUMO
A doença de Alzheimer (DA), principal doença neurodegenerativa relacionada à idade, é a causa mais comum de prejuízos cognitivos em pessoas com mais de 65 anos de idade, com custos mundiais estimados em U\$ 1 trilhão de dólares ao ano. Até 2050, estima-se que mais de $1 \%$ da população mundial desenvolva a DA. Contudo, os atuais tratamentos são paliativos e sintomáticos, sendo que um tratamento específico para modificar o curso da doença permanece além do alcance. Diante de tais dificuldades, esta revisão objetivou discutir criticamente algumas questões fundamentais acerca da vasta gama de Estudos cínicos e pré-clínicos realizados visando o desenvolvimento de fármacos para o tratamento da DA, enfatizando os obstáculos e as dificuldades existentes no atual cenário.
\end{abstract}

Amyloid hypothesis and treatment of Alzheimer's disease:review of clinical studies performed.

\section{ABSTRACT}

Alzheimer's disease $(\mathrm{AD})$ is the most common cause of dementia with an estimated prevalence of 47 million people worldwide, and with estimated global costs to be US \$ 1 trillion per year. However, the current treatments are palliative and symptomatic, and a specific treatment to modify the course of the disease remains beyond reach. Faced with such difficulties, the present review aim to critically discuss some fundamental questions about the wide range of clinical and preclinical studies carried out aiming at the development of drugs for the treatment of $\mathrm{AD}$, emphasizing the obstacles and difficulties existing in the current scenario.

\section{Introdução}

Os principais transtornos mentais representam um enorme fardo em termos de sofrimento humano e custo econômico e, de acordo com as estimativas recentes, correspondem a aproximadamente 32,4\% dos Anos Vividos com Incapacidades e 13\% da Esperança de Vida Corrigida pela Incapacidade (EVCI), números similares às doenças do aparelho cardiovascular (13,5\% - EVCI), superando o câncer (8,1\% - EVCI) (1). Embora os fármacos neuropsiquiátricos tenham sido extremamente rentáveis ao longo das últimas décadas, o desenvolvimento de novos fármacos está estagnado e, durante a última década, poucos fármacos obtiveram aprovação em comparação com outras áreas terapêuticas $(2,3)$. A Tabela 1 ilustra o número total de entidades moleculares aprovadas pela Agência Americana de Regulação de Alimentos e Medicamentos, a US Food and Drug

\footnotetext{
*Autor correspondente: eslenneuro@gmail.com (Delanogare E.)
} 
Administration (FDA), nesta década, e quantas delas possuem indicações para patologias relacionadas ao Sistema Nervoso Central (SNC).

Tabela 1 - Relação do número total de fármacos aprovados pela FDA nos últimos anos e o número de fármacos com indicações de atuação no SNC.

\begin{tabular}{c|c|c|c}
\hline Ano & Entidades MolecularesAprovadas & Indicações para o SNC & Referências \\
\hline 2010 & 21 & 3 & $(4)$ \\
\hline 2011 & 30 & 5 & $(5)$ \\
\hline 2012 & 39 & 2 & $(6)$ \\
\hline 2013 & 27 & 3 & $(7)$ \\
\hline 2014 & 41 & 4 & $(8)$ \\
\hline 2015 & 45 & 3 & $(9)$ \\
\hline 2016 & 22 & 4 & $(10)$ \\
\hline 2017 & 46 & 6 & $(11)$ \\
\hline
\end{tabular}

Ademais, o mecanismo de ação dos antidepressivos, ansiolíticos e antipsicóticos amplamente utilizados permanece relativamente inalterado em relação aos protótipos dos anos de 1950 (3). Ainda que progressos significativos em termos de segurança e tolerabilidade tenham sido obtidos, os novos fármacos não conseguiram atingir uma maior eficácia (2,3). De fato, a identificação de novos alvos terapêuticos e o desenvolvimento de novos fármacos neuropsiquiátricos se mostra uma tarefa especialmente árdua e complexa (12). Por exemplo, em comparação com outras classes terapêuticas, os fármacos neuropsiquiátricos apresentam maiores custos, prazos para aprovação e risco de insucesso em ensaios clínicos (13). Em outras palavras, as perspectivas de sucesso são desencorajadoras ao ponto de grandes empresas farmacêuticas, como a Pfizer, estarem reduzindo ou mesmo eliminando seus programas de pesquisa e desenvolvimento (P\&D) em neurociências $(14,15)$. A saída de empresas farmacêuticas deste mercado, mesmo diante de uma grande e crescente demanda, enfatiza as dificuldades das pesquisas relacionadas ao encéfalo e chama a atenção às limitações e desafios que existem para a pesquisa translacional (2). Mais importante, no entanto, é o fato de que existem diversas lacunas nos tratamentos, resultando em necessidades clínicas não atendidas (16).

Em especial, o desenvolvimento de fármacos para o tratamento de doenças neurodegenerativas tem sido particularmente baixo (e.g., menos de $10 \%$ dos fármacos visando doenças neurológicas e transtornos mentais são aprovados para o tratamento de destas doenças) (17). Especificamente, a doença de Alzheimer (DA) é uma das doenças neurodegenerativas mais devastadoras e se caracteriza como o principal tipo de demência, afetando mais de 47 milhões de pessoas em todo o mundo. Esses números devem crescer drasticamente em virtude do fenômeno de envelhecimento populacional, estimando-se que até 2050, uma em cada oitenta e cinco pessoas desenvolva a DA (18). Esta doença neurodegenerativa crônica prejudica a memória do paciente, reduzindo a capacidade de julgamento e raciocínio, levando a uma miríade de sintomas comportamentais e psiquiátricos (19). Neste sentido, o custo mundial da demência para a sociedade é estimado em US\$ 1 trilhão de dólares, destacando o enorme impacto socioeconômico em todo o mundo (18).

Em particular, o desenvolvimento de novos fármacos ao tratamento da DA tem sido decepcionante. Até o momento, os fármacos aprovados são os inibidores da enzima acetilcolinesterase (i.e., tacrina, donepezil, galantamina e rivastigmina, aprovados em 1993, 1996, 1996 e 2000, respectivamente) e o antagonista fraco dos receptores N-metil-D-aspartato (NMDA), memantina, aprovada em 2003 (20, 21). Contudo, esses tratamentos são paliativos e sintomáticos, sendo que um tratamento 
específico para modificar o curso da doença permanece além do alcance (21-23). De fato, apesar dos vultosos investimentos em $\mathrm{P} \& \mathrm{D}$, nenhum novo fármaco é aprovado desde 2003 (21, 24). Por exemplo, a taxa global de sucesso para novas entidades moleculares, entre os anos 2002 a 2012, foi de apenas uma em 244, ou seja, uma taxa de insucesso de 99,6\% (21). Consequentemente, há um amplo debate acercada fisiopatologia da DA e possíveis melhorias nos critérios diagnósticos, escolha de alvos terapêuticos, desenvolvimento de candidatos a medicamentos e desenho de ensaios clínicos $(22,24,25)$.

Neste sentido, para acelerar o desenvolvimento de fármacos neuropsiquiátricos, o Institute of Medicine's Forum on Neuroscience and Nervous System Disorders (IOM) organizou uma série de simpósios para discutir os desafios e oportunidades da neurociência translacional (26). Os principais desafios em torno das práticas atuais de desenvolvimento terapêutico que o IOM explorou podem ser resumidos da seguinte forma: a) mecanismos de doença, b) identificação e validação de alvos terapêuticos, c) modelos experimentais preditivos, d) biomarcadores para estratificação de pacientes e para endpoints em ensaios clínicos, e) trâmites de regulamentação claros, f) confiabilidade e reprodutibilidade de dados científicos publicados e g) compartilhamento de dados e colaboração (16). Com estes desafios em mente, esta revisão tem como objetivo discutir criticamente vários obstáculos no atual cenário de desenvolvimento de fármacos ao tratamento da DA, com um foco particular nas principais lacunas e desafios que podem ter um importante impacto no tratamento da DA nos próximos anos.

\section{2. “Hipótese da cascata amiloide" e falhas clínicas}

O desenvolvimento de fármacos, desde a descoberta inicial de um alvo promissor até a medicação final, é um processo complexo que pode levar entre 12 e 15 anos e pode custar mais de US\$ 1 bilhão de dólares, incluindo o custo das falhas (7). Neste contexto, praticamente toda a pesquisa científica básica que contribui para a descoberta de um medicamento inovador ocorre em laboratórios acadêmicos e institutos de pesquisa (17). Em particular, esta pesquisa inicial resulta em dados que permitem desenvolver hipóteses de que a inibição ou ativação de determinada proteína ou via resultará em um efeito terapêutico sobre determinada patologia, ou seja, a identificação de um alvo terapêutico, um passo crítico na descoberta de novos fármacos (27). Uma vez que um alvo é identificado, é necessária, ainda, uma demonstração adicional de que ele está diretamente envolvido no processo da doença, e que a modulação desse alvo provavelmente terá um efeito terapêutico, ou seja, a validação do alvo. Quando um alvo potencialmente relevante para uma doença é validado, uma busca intensiva para encontrar novas moléculas (séries de compostos) se inicia, sendo estas tipicamente chamadas de compostos-protótipo, que serão testadas acerca de suas atividades biológicas, evoluindo para o desenvolvimento pré-clínico e, caso seja bem-sucedido, em desenvolvimento clínico e, em última análise, um medicamento comercializado (27).

Em geral, a seleção do alvo biológico para um programa de descoberta de fármacos é uma das decisões mais importantes que uma equipe de desenvolvimento fará (28). Em particular, a identificação do alvo depende de um profundo conhecimento da neuropatologia da doença. Nesse sentido, embora a causa fundamental da DA permaneça desconhecida, a hipótese da cascata amiloide é atualmente, o quadro conceitual mais bem definido e mais bem descrito $(29,30,31)$. A hipótese da cascata amiloide fora originalmente formulada com base em evidências patológicas: duas características patológicas da DA são as placas amiloides extracelulares e os emaranhados intraneuronais de uma forma agregada da proteína Tau (32). O peptídeo beta-amiloide (A $\beta$ ), de 36 a 43 aminoácidos de comprimento, é um produto do processamento proteolítico da proteína 
precursora amiloide (APP), uma proteína transmembranar do tipo I (33). A clivagem da APP pela enzima $\beta$-secretase (BACE-1) gera um fragmento do terminal C ( $\beta$-CTF), que é um substrato imediato para a enzima $\gamma$-secretase que cliva este $\beta$-CTF para produzir um espectro de peptídeos $\mathrm{A} \beta$ com diferentes comprimentos, i.e., via amiloidogênica (34). A principal forma de $A \beta$ é de 40 aminoácidos $\left(A \beta_{1-40}\right)$, mas a forma menos abundante de 42 aminoácidos $\left(\mathrm{A} \beta_{1-42}\right)$ é mais amiloidogênica (30). Em contrapartida, a clivagem de APP por meio da enzima $\alpha$-secretase gera um terminal $C$ que sofre clivagem da $\gamma$-secretase, dita via não amiloidogênica, e resulta na produção de um fragmento APP mais curto, possivelmente inócuo (p3), impedindo assim a formação de $A \beta(35)$, conforme ilustrado na Figura 1.

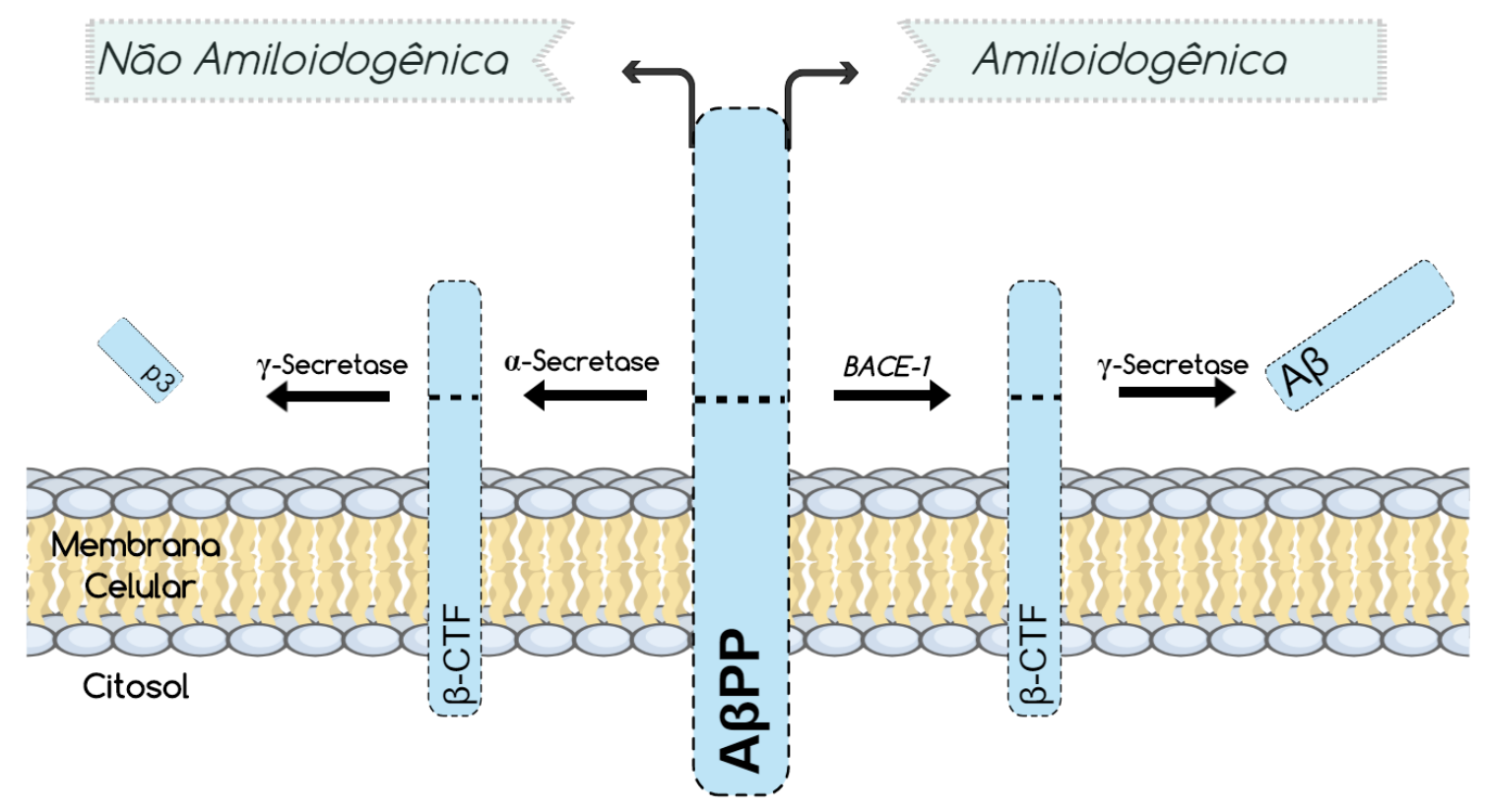

Figura 1 - Processamento da Proteína Percursora Amiloide (APP). BACE-1: $\beta$-secretase; APP: proteína precursora amiloide; $\beta$-CTF: fragmento do terminal C. Adaptado de Querfurth e LaFerla, 2010 (36).

De acordo com a hipótese da cascata amiloide, um desequilíbrio entre a produção e a depuração do peptídeo $A \beta$ é um processo chave na complexa cascata patológica da DA (30, 37). Os peptídeos $A \beta$ solúveis se agregam espontaneamente para formar oligômeros e fibrilas $\mathrm{A} \beta$ que são subsequentemente depositados no encéfalo para formar placas amiloides de núcleo difuso e denso $(30,38)$. Em primeiro lugar, a superprodução do peptídeo $\mathrm{A} \beta$ ou, mais frequentemente, a perda de depuração no encéfalo, provavelmente estão associadas à formação de oligômeros, que causam desregulação na estrutura e função sináptica (39). Além disso, a deposição de $\mathrm{A} \beta$ no parênquima cerebral está associada a uma resposta inflamatória robusta (40). Ao longo do tempo, também são observadas condições de estresse oxidativo, homeostase iônica alterada e uma série de mudanças bioquímicas adicionais. Esta cascata patológica - a saber, a hipótese da cascata amiloide - culmina na disfunção sináptica/neuronal disseminada e morte celular (29 - 31).

Não surpreende, assim, que o $A \beta$ tenha se tornado um importante alvo terapêutico para o desenvolvimento de fármacos para a DA (41). De fato, esta hipótese proporcionou um quadro coerente para a compreensão da patogênese da DA (ou seja, mecanismos da doença), sendo que várias abordagens farmacológicas que visavam o peptídeo amiloide estariam cientificamente fundamentadas para entrar no desenvolvimento pré-clínico e 
clínico, isto é, identificação e validação do alvo (23). Embora o acúmulo de $\mathrm{A} \beta$ no encéfalo seja, provavelmente, multifatorial na DA esporádica de início tardio (em contraste com a DA de início precoce autossômico dominante), é plausível que as intervenções direcionadas à hipótese amiloide possam produzir benefício clínico em todas as formas de DA (42). Com base nessas premissas, quatro estratégias principais foram desenvolvidas para reduzir as concentrações de $A \beta$ no encéfalo: (i) prevenção ou redução da formação de $A \beta$, principalmente por meio da inibição de enzimas proteolíticas que medeiam $o$ processamento amiloidogênico da APP ( $\beta$-secretase e $\gamma$-secretase); (ii) remoção de depósitos amiloides existentes por meio de imunoterapia (imunização passiva ou ativa); (iii) prevenção ou redução da agregação de $\mathrm{A} \beta$; e (iv) aumento da depuração de $\mathrm{A} \beta(38,43)$.

No entanto, embora os esforços para traduzir as informações científicas acerca da DA em novos fármacos sejam enormes, ao momento nenhum fármaco relacionado à hipótese amiloide demonstrou eficácia em ensaios clínicos de fase III. Por exemplo, os ensaios clínicos de fase III com o bapineuzumab, da Johnson \& Johnson e Pfizer Inc., e com o solanezumab, da Eli Lilly \&Co., anticorpos voltados para a remoção de A $\beta$, falharam em seus parâmetros primários em pacientes com DA leve a moderada $(44,45)$. Vale ressaltar que o solanezumab alterou os níveis de $\mathrm{A} \beta$ no líquido plasmático e cefalorraquidiano (LCR), dados que demonstram o engajamento entre o fármaco e o seu alvo terapêutico (44). Destaca-se um estudo de fase III duplo-cego controlado por placebo, envolvendo pacientes com DA leve, os quais apresentaram deposição amiloide revelada por meio de tomografia de emissão de pósitrons (florbetapir) e medições de $\mathrm{A} \beta_{1-42}$ no LCR. Neste estudo, os pacientes foram aleatoriamente designados para receber solanezumab na dose de $400 \mathrm{mg}$ ou placebo por via intravenosa (i.v.), a cada 4 semanas por 76 semanas. Um total de 2.129 pacientes foram inscritos, dos quais 1057 foram designados para receber solanezumab e 1072 para receber placebo. Os resultados não mostraram diferença significativa sobre o desfecho primário. Em especial, os dados mostraram que o solanezumab não foi eficaz para evitar o declínio cognitivo nos pacientes com DA envolvidos no estudo (46). Além disso, um ensaio clínico de fase III com o semagacestat (Eli Lilly \&Co), inibidor da enzima $\gamma$-secretase, não apresentou benefício ao tratamento de DA leve a moderada (47). Aliás, o tratamento com semagacestat foi associado com piora clínica dose-dependente em múltiplas medidas de desfechos primários e secundários, incluindo medidas de atividades diárias (índice ADCS-ADL), variáveis clínicas preditivas de deterioração cognitiva pelo Miniexame do Estado Mental (MMSE) e qualidade de vida (EQ-5D) (47). Além disso, outras terapias direcionadas ao $A \beta$ claramente não tiveram sucesso até o momento. Apesar de ter sido reduzido a concentração de $A \beta_{42}$ no LCR e no plasma de indivíduos saudáveis, o tarenflurbil (modificador de $\gamma$-secretase) não demonstrou melhora clínica em pacientes com DA leve à moderada em um ensaio de fase III $(48,49)$. Ademais, o tramiprosate, que impede a agregação do $\mathrm{A} \beta$, também não cumpriu os desfechos primários em um ensaio de fase III (50).

Por outro lado, os inibidores da enzima $\beta$-secretase (BACE-1) também levantam esperanças de que terapias modificadoras da DA estejam ao alcance (51). Em um estudo clínico de fase I, randomizado, duplo-cego, placebo controlado, o inibidor da $\beta$-secretase MK-8931, da Merck e Co., foi bem tolerado e demonstrou uma redução pronunciada de até $94 \%$ nos níveis de $A \beta_{40}$ e $A \beta_{42}$ no LCR (52). Além disso, em um estudo de fase II, randomizado, duplo-cego, placebo controlado, em pacientes com DA leve a moderada, a administração de MK-8931 resultou em uma redução dose-dependente nos níveis de A $\beta$ do LCR, semelhante ao observado em voluntários saudáveis (53). De acordo com o estudo, os perfis dose-resposta preveem que entre 12 e $40 \mathrm{mg}$ de MK-8931 inibam a produção de $\mathrm{A} \beta$ em até $50 \%$ e $75 \%$, respectivamente, na maioria dos pacientes com DA 
(53). Contudo, recentemente, o MK-8931, da Merck e Co., estava sendo investigado em estudos de fase III para avaliação de sua eficácia e segurança no tratamento de comprometimento cognitivo leve (Clinical Trials.gov Identifiers: NCT01953601 e NCT01739348) e os resultados demonstraram que o mesmo não reduziu o declínio cognitivo e teve efeitos adversos no tratamento da DA leve e moderada, levando ao cancelamento dos ensaios (54).

Em geral, nos últimos 20 anos, a hipótese amiloide influenciou significativamente as atividades de $\mathrm{P} \& \mathrm{D}$, visando desenvolver novos fármacos para o tratamento da DA, contudo nenhum agente terapêutico "amiloidocêntrico" atingiu os desfechos primários. Neste sentido, embora a hipótese amiloide seja a teoria mais proeminente da patologia da DA, vários achados também são contrários aos seus princípios. Por exemplo, a deposição de $\mathrm{A} \beta$ ocorre em indivíduos cognitivamente normais; a patologia amiloide não se correlaciona bem com declínio cognitivo ou perda de sinapse na DA; demonstração de repetidos insucessos com ensaios clínicos centrados no $A \beta$; e diversos estudos que mostraram que os emaranhados neurofibrilares se correlacionam com a gravidade da demência $(55,56,57)$. Na verdade, um crescente número de evidências mostra que os peptídeos $A \beta$ provavelmente não constituem o único fator na etiologia da DA $(55,57)$. De acordo com Pimplikar (56), uma visão de que A $\beta$ é um dos fatores, em oposição ao fator, que causa a DA é mais consistente com o conhecimento atual e é mais provável que resulte em estratégias terapêuticas abrangentes e eficazes. Por outro lado, é importante notar que a falta de eficácia clínica é a causa mais frequente de descontinuação de um programa de desenvolvimento de medicamentos $(58,59)$. Em particular, o alto insucesso de moléculas em ensaios clínicos tem sugerido que os modelos animais de DA não apresentam boa predição, ao menos em termos de neuroproteção, para eficácia em seres humanos $(60,61)$.

De fato, muita esperança foi depositada em modelos experimentais de DA utilizando roedores, em sua maioria construídos e embasados na hipótese amiloide, como modelos preditivos para novas terapias (57). Uma vez que os modelos de DA em roedores foram amplamente centrados no $\mathrm{A} \beta$, uma miríade de estudos pré-clínicos que testaram tratamentos anti-amiloides produziu resultados positivos (e.g., redução da deposição de placas amiloides) e um grande entusiasmo pelos ensaios terapêuticos centrados em A $\beta$ surgiu. Nas próximas seções, discutiremos algumas questões importantes em torno da vasta gama de estudos de terapias anti-amiloides e demonstraremos que os efeitos positivos observados em modelos animais raramente são paralelos ao sucesso semelhante em pacientes com DA.

\section{Modelos experimentais de DA ou modelos experimentais de patologias relacionadas ao beta-amilóide?}

Os modelos animais são indispensáveis ao processo de descoberta e desenvolvimento de fármacos (62). Por exemplo, a eficácia de um composto-protótipo em um modelo animal de doença representa um passo importante na validação do alvo terapêutico e, dentro da indústria, pode representar um importante ponto de decisão "prosseguir/não-prosseguir" antes de chegar aos estudos clínicos (16). Além disso, como enfatizado por Cook e colaboradores (28), a confiança no "alvo certo" baseia-se no desenvolvimento de uma boa plataforma de evidências em estudos pré-clínicos e, em particular, no nível de confiança de que os dados desses estudos são traduzíveis para doenças humanas.

No entanto, esta tarefa é particularmente difícil para as patologias do SNC em decorrência da escassez de informações acerca dos processos fisiopatológicos, suas origens genéticas e epigenéticas, bem como da natureza heterogênea de muitas dessas condições e os desfechos subjetivos e, às vezes, contraditórios que são usados para descrever seus sintomas e 
gravidade (63). Portanto, não surpreende que a falha de modelos animais em prever a eficácia de moléculas com novos mecanismos de ação para patologias do SNC venha sendo um gargalo central no desenvolvimento de novos fármacos.

Em particular, a modelagem de doenças neurodegenerativas humanas, como a DA, em animais, é um desafio. Por exemplo, poucas espécies desenvolvem espontaneamente placas amiloides e exibem tauopatias. Entre eles, cães $(64,65)$, gatos (66), ursos polares $(67,68)$, cabras (69), bem como várias espécies de primatas não humanos $(70,71,72)$. Entretanto, seu uso para pesquisa experimental é limitado pela disponibilidade, economia e/ou razões éticas (73). Por outro lado, os roedores idosos (e.g., com cerca de 20 meses de idade) não desenvolvem, espontaneamente, características histopatológicas semelhantes à DA e, portanto, não são úteis ao desenvolvimento de fármacos que visam estes alvos terapêuticos (73). A contribuição de roedores idosos, no que tange a descoberta de medicamentos relacionados à DA, baseia-se na ocorrência de alterações cognitivas e comportamentais relacionadas à senescência, associadas a alterações neuroquímicas e morfológicas relevantes para DA, incluindo hipofunção colinérgica associada à idade $(74,75)$.

Aproximadamente 5\% dos pacientes com DA enquadram-se na categoria de doença de Alzheimer Familiar (DAF), uma forma precoce de DA que está relacionada a uma forte predisposição genética, com mutações no gene da APP no cromossomo 21 , gene da presenilina1 (PS1) no cromossomo 14 e o gene da presenilina 2 no cromossomo 1 (34). Embora muitos genes envolvidos com a susceptibilidade para DA tenham sido relatados, o único fator de risco genético fortemente confirmado em muitos estudos para DA precoce e tardia é o genótipo da Apolipoproteína E (APOE), sendo o alelo $\varepsilon 4 \mathrm{um}$ fator de risco e o alelo $\varepsilon 2$ um fator protetor $(76,77)$. De particular importância, a descoberta desses polimorfismos relacionados à doença em genes que codificam tanto a APP como as enzimas que convertem esta proteína em fragmentos amiloidogênicos, proporcionou forte evidência de um papel fundamental das placas amiloides no desenvolvimento da DA. Esses casos familiares proporcionaram, assim, evidências genéticas que têm sido utilizadas no desenvolvimento de animais transgênicos como modelos experimentais da DA. De fato, nas últimas duas décadas, diversos modelos de DA foram desenvolvidos com o intuito de mimetizar a causa genética da humana, por meio de camundongos transgênicos que superexpressam formas mutantes de APP humana, presenilinas e/ou proteína tau no encéfalo (78). Atualmente, camundongos transgênicos que superexpressam formas mutadas de APP são considerados um modelo animal preditivo (79). Muitos dos modelos de DA transgênicos desenvolvidos exibem acúmulo de $\mathrm{A} \beta$, acúmulo de placas amiloides, gliose, perda neuronal, patologia tau e/ou comprometimentos cognitivos, mas nenhum modelo de DA transgênico, isoladamente, recapitula todos os aspectos da patologia da DA (para uma visão abrangente dos recentes modelos animais na pesquisa $\mathrm{AD}$, ver 79), o que pode explicar, em parte, a dificuldade translacional, uma vez que os animais não apresentam efetivamente a DA, apenas características encontradas nela (80).

Além disso, as características neuropatológicas relacionadas com o $\mathrm{A} \beta$ de pacientes com DA podem ser mimetizadas por infusão intracerebral ou intracerebroventricular de peptídeos $A \beta$ em diferentes concentrações no encéfalo de roedores (19). Peptídeos $A \beta$ podem ser administrados de forma aguda, usando uma única injeção estereotáxica, ou repetitivamente, usando injeções por meio de uma cânula. Para melhor mimetizar a lenta evolução da DA, a administração crônica e contínua é obtida usando-se a micro diálise ou uma cânula ligada a uma minibomba osmótica ou bomba de micro infusão. A infusão de peptídeos $\mathrm{A} \beta$ pode levar a alterações comportamentais relacionadas à DA (como atividade $\mathrm{e}$ exploração diminuídas), comprometimento cognitivo e hipofunção colinérgica (73). 
Em particular, os estudos de DA familiar motivam a descoberta de fatores genéticos responsáveis pela DA. Durante décadas os pesquisadores focaram principalmente na via iniciada pela agregação de $\mathrm{A} \beta$, deposição amiloide e seu acúmulo como o mecanismo chave subjacente à doença, tendo esta via como alvo terapêutico mais importante (81). Nesse sentido, a descoberta de fármacos para a DA poderia envolver a hipótese de que o "composto $X$ " reduzirá a concentração de $A \beta_{1-42}$ em camundongos transgênicos. Se o tratamento alcançar a prova de conceito (PoC) desejada, isto é, se um regime de administração de um dado composto for eficaz para diminuir a concentração de $A \beta_{1-42}$ no LCR, obtém-se uma PoC para encorajar o desenvolvimento adicional desta molécula (59). No entanto, estudos pré-clínicos nesses camundongos não foram bem-sucedidos, pelo menos em termos de sua capacidade de prever os resultados de ensaios clínicos em humanos. Por exemplo, uma extensa gama de estudos de terapias anti-amiloides demonstrou que os efeitos positivos observados em modelos animais raramente são acompanhados por sucesso semelhante em pacientes com DA $(21,80)$.

\subsection{Semagacestat}

O semagacestat é um inibidor da $\gamma$-secretase (gama secretase) que reduz a produção de

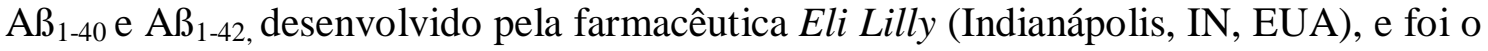
primeiro inibidor da $\gamma$-secretase aprovado para ensaios clínicos de fase III. A atividade da $\gamma$-secretaseé importante para a liberação do peptídeo A $\beta$ depois que a APP é clivada pela BACE-1 (Figura 1). Sabendo disso, a utilização de um inibidor desta enzima deverá reduzir a produção de $A \beta$.

$\mathrm{Na}$ interpretação mais simples da hipótese amiloide, que postula que a deposição contínua de $A \beta$ resulta em processos patológicos causadores de disfunção sináptica e morte neuronal, um inibidor da $\gamma$-secretase reduziria a produção de $A \beta$ e retardaria a progressão da DA (23). De fato, os efeitos do semagacestat nas concentrações de A $\beta$ no encéfalo, LCR e plasma foram bem caracterizados em camundongos transgênicos e não transgênicos $(82,83,84)$. Nos camundongos transgênicos PDAPP, os quais exibem uma alta expressão de APP humana, foi demonstrada uma inibição, dose-dependente, na produção de $A \beta$ no hipocampo após a administração de semagacestat durante 7 dias (82). Por outro lado, ensaios clínicos preliminares de fase II demonstraram apenas uma redução de $\mathrm{A} \beta$ plasmática, mas não no $\operatorname{LCR}(85,86,87)$.

Em um estudo crônico, o semagacestat foi administrado diariamente em camundongos PDAPP, com 5 meses de idade, por 5 meses, nas doses de 3, 10 e $30 \mathrm{mg} / \mathrm{kg}$ (84). Foi observada uma redução da concentração de $\mathrm{A} \beta$ no córtex e no hipocampo, dose-dependente em relação aos grupos controle que receberam placebo. Contudo, não houve redução significativa no acúmulo de placas amiloides analisadas por meio das análises de imuno-histoquímica. Assim, esses dados são indicativos de que a dosagem de semagacestat reflete um paradigma de prevenção e não terapêutico. De fato, vários estudos demonstraram que os inibidores da $\gamma$-secretase impedem a formação de novas placas $A \beta$, mas mesmo com significativa supressão da produção de $\mathrm{A} \beta$, não medeiam a depuração das placas existentes $(23,88)$. Desta forma, devido à possibilidade de o semagacestat ter efeitos modificadores da doença em pacientes com DA, a farmacêutica Eli Lilly lançou dois ensaios multinacionais de fase III (ClinicalTrials.gov: NCT00594568 e NTC00762411) comparando as duas doses usadas em estudos de fase II (100 e $140 \mathrm{mg}$ uma vez ao dia) com placebo, em um estudo randomizado e duplo-cego. No entanto, estes dois ensaios clínicos de fase III falharam na demonstração de sua eficácia, os quais ainda sofreram interrupção precoce devido a efeitos colaterais graves, incluindo toxicidade hematológica, gastrointestinal e cutânea, que foram atribuídos à inibição da via de sinalização de 
Notch $(47,89)$. Surpreendentemente, no entanto, não foi observada melhora ou piora em medidas cognitivas nestes estudos. A esse respeito, Strooper (90) apresentou recentemente algumas razões para o insucesso nesses ensaios clínicos. Em primeiro lugar, ele destaca o curto tempo de meia-vida do semagacestat ( $2-3$ horas): assim, uma única dose da droga é completamente removida do LCR após 12 horas (91). Além disso, o medo de efeitos colaterais levou os pesquisadores a administrar o fármaco apenas uma vez por dia, ao contrário de duas vezes ao dia, como originalmente planejado (90). Segundo Strooper (90), pode-se deduzir que, na maior parte do dia, os pacientes não tinham concentrações detectáveis do fármaco no encéfalo, produzindo, assim, quantidades normais de A $\beta$. Ainda, foi demonstrado que quando o fármaco atingia concentrações muito baixas, estas, paradoxalmente, estimulavama produção de $\mathrm{A} \beta$ (92), que poderia ter neutralizado ainda mais os efeitos sobre A $\beta$ no LCR e pode ter levado a um "jogo de soma zero" (90). Segundo o pesquisador, uma menor dosagem do fármaco em um regime mais crônico poderia ter atenuado os efeitos adversos.

\subsection{Bapineuzumab}

Obapineuzumab é uma forma humanizada do anticorpo murino 3D6, um anticorpo monoclonal altamente específico criado a partir de resíduos de $\mathrm{A} \beta$ (93), derivado da IgG1, que apresenta como alvo a porção $N$ terminal da $A \beta$ (94). Ele atua ligando-se às formas fibrilares e solúveis de $\mathrm{A} \beta$, ativando as células da micróglia, o que leva à indução da fagocitose (95). Ensaios pré-clínicos de Bard (95) e Zago (96) demonstraram uma redução do número de placas amiloides e melhoras nos déficits cognitivos.

O desenvolvimento do bapineuzumab decorreu de um estudo inovador, demonstrando que a imunização de camundongos transgênicos PDAPP com o peptídeo $A \beta_{42}$ foi capaz de prevenir a deposição de placas $A \beta$ no parênquima cerebral (97). De fato, camundongos PDAPP, com 11 meses de idade, tratados com injeções semanais de 3D6 por seis meses tiveram expressiva redução da carga de placas $A \beta$, chegando a $86 \%$ (95). Além disso, Seuberte colaboradores (98) realizaram três estudos em camundongos transgênicos PDAPP. Em um estudo preventivo, o 3D6 (IgG2a) foi administrado por meio da via intraperitoneal na dose de $10 \mathrm{mg} / \mathrm{kg} / \mathrm{semana}$ em camundongos de 4 meses de idade, por 12 meses. $\mathrm{O}$ tratamento com 3D6 reduziu o acúmulo de placas A $\beta$ em $89 \%$. Quando o 3D6 foi administrado em um estudo terapêutico em camundongos de 12 meses de idade na dose de $3 \mathrm{mg} / \mathrm{kg} / \mathrm{semana}$ por seis meses, houve uma redução de $93 \%$ na marcação para depósito de A $\beta$ por imuno-histoquímica em comparação com os controles (98). A partir disso, quatro ensaios clínicos de fase III, randomizados, duplo-cego e placebo controlados foram iniciados envolvendo um total de 4570 pacientes com DA leve a moderada. Dois estudos separados foram conduzidos em portadores e não portadores de APOE4, predominantemente na América do Norte (ClinicalTrials.gov identificadores NCT00575055 e NCT00574132); 2 ensaios paralelos foram realizados predominantemente no resto do mundo (ClinicalTrials.gov identificadores NCT00667810 e NCT00676143). O bapineuzumab foi administrado em pacientes que eram portadores de APOE4 a 0,5mg/kg e em não portadores a $0,5 \mathrm{mg} / \mathrm{kg}, 1 \mathrm{mg} / \mathrm{kg}$ e $2 \mathrm{mg} / \mathrm{kg}$ inicialmente, com a dose de $2 \mathrm{mg} / \mathrm{kg}$ sendo abandonada devidoao aparecimento de edemas. $\mathrm{O}$ bapineuzumab não atingiu os desfechos cognitivos primários nos ensaios NCT00575055 e NCT00574132 (45). Consequentemente, os ensaios NCT00667810 e NCT00676143 foram encerrados por não demonstrarem efeitos terapêuticos (99). Embora modesta, houve uma redução na marcação de placas amiloides vistas por ressonância magnética por imagem em portadores de APOE4 quando comparados a placebos. Em dados agrupados dos ensaios NCT00575055 e NCT00574132, houve um aumento significativo, mas modesto, na atrofia cerebral devido 
ao tratamento com bapineuzumab. Com base em tais resultados, a Pfizer e a Johnson \& Johnson abandonaram o desenvolvimento do bapineuzumab.

\subsection{Solanezumab (m266)}

O Solanezumab é um anticorpo IgG1 humanizado derivado do anticorpo monoclonal m266 de ratos. Seubertet al (100) foram os primeiros a mostrar que uma forma solúvel do $A \beta_{13-28}$ se encontra em fluídos humanos como, por exemplo, o plasma (100). Posteriormente, foram realizados estudos que mostraram que a geração de $A \beta$ ocorre em tipos celulares do SNC e também do Sistema Nervoso Periférico (SNP) (101). O m266 tem a capacidade de se ligar a monômeros e dímeros de $\mathrm{A} \beta$ na periferia e, embora sua ação seja incerta, a hipótese é de que esse anticorpo é capaz de neutralizar as formas tóxicas solúveis de $A \beta$ cerebral. No entanto, em camundongos transgênicos que superexpressam a APP humana, o m266 aumentou o A $\beta$ no sangue e no encéfalo (102). De Mattos e colaboradores (103) demonstraram que a administração i.v. de $0,5 \mathrm{mg} / \mathrm{Kg}$ de m266 em camundongos PDAPP foi capaz de reduzir os depósitos de A $\beta$ no córtex que está sobreposto ao hipocampo dos animais, demonstrando uma correlação positiva entre a concentração de amiloide no hipocampo e a quantidade total de $\mathrm{A} \beta$ no plasma aferido após 24 horas. Este resultado estabeleceu que o m266 administrado perifericamente foi capaz de promover a depuração periférica de A $\beta$. Embora a administração periférica de m266 em camundongos PDAPP reduza acentuadamente a deposição de $A \beta$, o m266 não alterou aos depósitos existentes de $A \beta$ no encéfalo (103). Assim, a hipótese para o tratamento com solanezumab foi que, ao administrar a versão humanizada de m266 - a saber, o solanezumab - a pacientes com DA, pauta-se no pressuposto de que o efluxo de $\mathrm{A} \beta$ dos encéfalos de pacientes com DA seria aumentado, levando, em última análise, à resolução ou diminuição do $\mathrm{A} \beta$ depositado. Entretanto, considerando que os dados que suportam os efeitos periféricos de m266 são robustos, a efetividade do tratamento com $\mathrm{m} 266$ sobre os depósitos de $\mathrm{A} \beta$ no parênquima não foram convincentes, representando um paradigma preventivo e não terapêutico (103). Seubert e colegas (98) realizaram administração intraperitoneal de m266 em doses de 3 e $10 \mathrm{mg} / \mathrm{kg}$ por semana em 2 estudos distintos. A dosagem fora iniciada aos 12 meses e continuada até os dezoito meses. Em nenhuma das doses o m266 mostrou-se efetivo em reduzir o A $\beta$ depositado no encéfalo dos animais.

Em dois ensaios duplo-cegos de fase III (Expedition 1 e 2), 1012 e 1040 pacientes, respectivamente, com DA leve a moderada foram aleatoriamente designados para receber placebo ou solanezumab (administrado por via i.v. na dose de $400 \mathrm{mg}$ ) a cada 4 semanas por 18 meses. Os desfechos primários foram as mudanças desde a linha de base nas pontuações da subescala cognitiva de 11 itens da Escala de Avaliação da doença de Alzheimer (ADAS- $\operatorname{cog} 11$; variação de 0 a 70, com escores mais altos indicando comprometimento cognitivo maior) e Estudos Cooperativos da doença de Alzheimer - atividades da vida diária (ADCS-ADL). Após a análise dos primeiros dados, o resultado primário da Expedição 2 foi revisado para a mudança na pontuação da subescala cognitiva de 14 itens da Escala de Avaliação da doença de Alzheimer (ADAS- $\operatorname{cog} 14$; variação de 0 a 90, com maiores escores indicando maior deficiência), em pacientes com DA leve. No entanto os resultados indicaram que o solanezumab falhou na tentativa de melhora cognitiva ou funcional (44).

Noutro estudo de fase III duplo-cego, randomizado e controlado por placebo, envolvendo pacientes com demência leve devido à DA, definida como um escore de 20 a 26 do MMSE e com deposição de Aßrevelada por meio de medições de $\mathrm{A} \beta_{42}$ no LCR, 1057 e 1072 pacientes foram aleatoriamente designados para receber solanezumab na dose de $400 \mathrm{mg}$ ou 
placebo, respectivamente, por via i.v. a cada 4 semanas por 76 semanas. O desfecho primário foi a mudança da linha de base para a semana 80 na pontuação da subescala cognitiva de 14 itens da ADAS-cog14. Os resultados demonstraram que o solanezumab não afetou significativamente o declínio cognitivo se comparado ao grupo que recebeu placebo (46). Embora em fases anteriores o solanezumab tenha apresentado efeitos adversos relacionados ao sistema cardiovascular (104), nesse estudo tais efeitos não foram observados, uma vez que não houve diferença significativa entre os efeitos colaterais do grupo tratado quando comparado ao placebo (46).

Em junho de 2016, a Eli Lilly \& Co. iniciou um estudo clínico de fase III (ClinicalTrials.gov: NCT02760602) em pacientes com DA prodrômica, isto é, pré-demência, onde 2450 pessoas com um diagnóstico clínico de DA prodrômica ou com comprometimento cognitivo leve (MCI) estavam participando do ensaio. O estudo teve duração prevista de dois anos e constava de uma infusão mensal de solanezumab ou placebo. O desfecho primário foi a mudança da linha de base na ADAS-Cog14, enquanto os 16 desfechos secundários listados seguiram a gama de medidas clínicas, cognitivas, funcionais, psiquiátricas e globais, bem como biomarcadores em exames de sangue, LCR e PET tanto para patologia amiloide quanto para tau. No entanto, o estudo foi encerrado devido as insuficientes evidências científicas de que o solanezumab demonstraria um benefício significativo para os participantes com DA prodrômica, conforme definido pelo protocolo do estudo. Mais recentemente o foco mudou para explorar tratamentos anti-amiloide sem estágios anteriores da doença. O solanezumab está sendo testado em ensaios clínicos de fase III em pacientes com DA assintomáticos para verificar sua efetividade (ClinicalTrials.gov: NCT02008357 e NCT01760005), com previsão de término para 2022 e 2023 , respectivamente.

\subsection{Aducanumab (BIIB037)}

O BIIB037 é um anticorpo monoclonal IgG1 totalmente humano de elevada afinidade contra um epítopo conformacional encontrado no peptídeo $A \beta$. Foi originalmente desenvolvido pela empresa suíça de biotecnologia Neurimmune a partir de doadores saudáveis, idosos, que eram cognitivamente normais. A proposta foi de que o sistema imunológico desses doadores havia resistido com sucesso à DA e que seus anticorpos poderiam ser transformados em terapêutica por um processo chamado "medicina translacional reversa". O BIIB037 se liga às formas agregadas de A $\beta$, e não ao monômero. Em estudos pré-clínicos, mostrou-se que um análogo do aducanumab é capaz de permear a barreira hematoencefálica, ter engajamento com o alvo e remover o A $\beta$ do encéfalo de camundongos transgênicos que apresentam placas amiloides $(105,106)$.

Um estudo de fase 1 (PRIME STUDY - ClinicalTrials: NCT01677572) feito pela Biogen, randomizado, duplo-cego e controlado por placebo, foi projetado para verificar a segurança, tolerabilidade, farmacocinética e farmacodinâmica de múltiplas doses do Aducanumab. Um total de 165 pacientes foram randomizados e tratados entre outubro de 2012 e janeiro de 2014 em 33 locais nos Estados Unidos. Os critérios para inclusão no estudo foram um diagnóstico clínico de $\mathrm{AD}$ prodrômica ou leve e de PET A $\beta$ visualmente positivo. Os participantes receberam mensalmente infusões intravenosas de placebo ou Aducanumab em doses de 1, 3, 6 ou 10mg/kg durante 12 meses. As medições de imagem por PET florbetapir, mostraram que o tratamento com Aducanumab reduziu as placas A $\beta$ no encéfalo de forma dose e tempo dependentes. Os efeitos colaterais mais comuns foram infecção do trato urinário e respiratório e cefaleia. Tal estudo mostrou que o Aducanumab permeia a barreira hematoencefálica e diminuiu significativamente as marcações por PET para placas $A \beta$. Ainda, considerando que pode ter levado até 20 anos para que o A $\beta$ se acumulasse em tais níveis nos pacientes do estudo PRIME, a cinética observada de 
remoção de $A \beta$ dentro de um período de 12 meses parece encorajadora para um tratamento modificador da doença nesses pacientes (107).

Atualmente dois estudos de fase III estão ativos para testar os efeitos do aducanumab em regime de administração mensal sobre os parâmetros de comprometimento cognitivo (ClinialTrials.gov: NCT02477800 e NCT02484547), ambos com previsão de término em 2022.

\subsection{Tarenflurbil}

O tarenflurbil, também designado como R-flurbiprofeno, é um enantiômero do flurbiprofeno. Caracteriza-se como um anti-inflamatório não-esteroidal (AINE), que atua inibindo a enzima ciclooxigenase- 2 e, consequentemente, inibindo a formação de prostaglandinas e diminuindo o processo inflamatório $(108,109)$. Quanto à DA, existe associação direta entre os sinais inflamatórios da micróglia, a deposição de proteína amiloide e a patogênese da doença (110). Assim, a proteína amiloide ativa a micróglia, elevando a expressão neuronal da ciclooxigenase-2, o que, por sua vez, potencializa o estresse oxidativo mediado pela proteína amiloide. As prostaglandinas derivadas da ciclooxigenase-2 colaboram com o processo inflamatório, induzindo a síntese de citocinas pró-inflamatórias nas células da glia e potencializando a excitotoxicidade glutamatérgica, o que, por sua vez, acelera a neurodegeneração. Assim, os inibidores específicos da ciclooxigenase- 2 são alternativa terapêutica, por reduzirem a produção central destas prostaglandinas $(111,112)$. Ou seja, pela ciclooxigenase-2 estar envolvida com processos inflamatórios, sua inibição pode atenuar o robusto processo inflamatório envolvido na DA.

A hipótese do uso de tarenflurbil na tentativa de reduzir a produção de $\mathrm{A} \beta_{42}$ pauta-se em dados epidemiológicos que sugerem que o uso de AINEs pode oferecer certa proteção contra o desenvolvimento da DA (113). A partir desses dados, os agentes anti-inflamatórios foram testados quanto à sua capacidade de afetar a produção de $\mathrm{A} \beta$ e, notavelmente, vários AINEs comumente prescritos como, por exemplo, o sulindaco, a indometacina e o ibuprofeno, reduziram a produção de $A \beta_{42}$. Tal supressão foi compensada por um aumento nos metabólitos $A \beta$ mais curtos, especialmente $A \beta_{38}$ (114-116). Importante salientar que esses agentes não são inibidores da $\gamma$-secretase, mas agem deslocando os locais de clivagem em favor da produção de formas mais curtas de $\mathrm{A} \beta$ (23). Em modelos animais, tais como camundongos, usados para mimetizar estados de DA, o flurbiprofeno reduziu seletivamente os níveis de $\mathrm{A} \beta_{42}(114)$.

Partindo desses dados promissores observados em animais, e com base em ensaios clínicos de fase I, lançou-se um estudo de fase II utilizando o tarenflurbil em pacientes com DA leve e moderada. Nesse estudo, 210 pacientes que tiveram escores no MMSE entre 15 e 26, foram aleatoriamente designados para receber tarenflurbil duas vezes por dia (400 ou $800 \mathrm{mg}$ ou placebo) por 12 meses. Os dados do estudo demonstraram que os pacientes com DA leve, na dose de $800 \mathrm{mg}$, apresentaram taxa de declínio cognitivo mais lenta em comparação com os tratados com placebo, sendo que o fármaco foi bem tolerado e com poucos efeitos adversos (117). Ensaios clínicos de fase II com doses mais elevadas $(800$ - $1600 \mathrm{mg} / \mathrm{dia})$ demonstraram boa tolerância ao fármaco, com melhoria funcional no grupo com DA leve a moderada, levando à realização de ensaios clínicos de fase III na dosagem mais elevada $(1600 \mathrm{mg} /$ dia $)(48,118)$.

Embora os dados apresentam um possível efeito terapêutico do tarenflurbil, percebem-se algumas confusões na forma como os achados foram analisados. Para Aisen (119) uma dificuldade é que a atividade modificadora da DA pode não ser evidente em estudo de fase II, tornando o resultado confuso e evidenciando as dificuldades metodológicas de tal ensaio. $\mathrm{O}$ estudo foi concebido para mostrar uma diminuição na taxa de declínio cognitivo 
e funcional na DA leve a moderada. Uma das análises mostrou aparente interação entre o tratamento e os escores cognitivos, o que resultou em uma análise de eficácia separada que, dessa forma, apontaram que o fármaco teve influência sobre as medidas de resultado (23). De fato, houve evidência de um efeito favorável do tratamento nas atividades da vida diária e na função global no subgrupo de pacientes com DA leve. No entanto, é razoável questionar sobre se esses resultados comprovariam, de fato, uma eficácia do tarenflurbil na desaceleração do declínio na DA. Verifica-se que, apesar de os dados terem sido consistentes com um efeito benéfico do tarenflurbilna DA leve, não se mostraram suficientemente conclusivos (119).

Contudo, um estudo multicêntrico, randomizado, duplo-cego, controlado com placebo, envolvendo pacientes com DA leve foi conduzido em 133 locais de pesquisa nos Estados Unidos. A intervenção foi a administração de tarenflurbil $800 \mathrm{mg}$ ou placebo, duas vezes ao dia. Desfechos de eficácia co-primários foram acerca da mudança da linha de base no $18^{\circ}$ mês na pontuação total na subescala da ADAS-Cog e Estudos Cooperativos da doença de Alzheimer - atividades da vida diária (ADCS-ADL). Dos 1684 participantes randomizados, 1649 foram incluídos na análise, e 1046 completaram o ensaio. Os dados demonstraram que o tarenflurbil não obteve resultados significativos sobre o declínio cognitivo e sobre as medidas de atividade diárias, além de manifestar efeitos colaterais como tonturas, anemias e infeções no grupo experimental/tarenflurbil (48).Com base nos resultados dos ensaios clínicos de fase III, a MyriadGenetics optou por descontinuar o medicamento (120).

Vellas (121), por sua vez, salienta que os resultados deste estudo levantam duas questões importantes: Primeiro, por que o estudo da fase III falhou em ser bem-sucedido? Segundo, o que pode ser aprendido com essa experiência para orientar o desenvolvimento futuro de tratamentos bem-sucedidos? De acordo com o pesquisador, embora esses resultados não sejam surpreendentes, não indicam, necessariamente, uma falha da abordagem anti-amiloides (121).

\subsection{Lanabecestat (LY3314814 ou AZD3293)}

O Lanabecestat é um inibidor da $\beta$-secretase (BACE1), enzima que cliva a proteína APP para liberar o fragmento C99 (122). Este fragmento torna-se, então, um substrato para a subsequente clivagem da $\gamma$-secretase e geração do peptídeo $A \beta$ (36). Em linhas gerais, a inibição da BACE1 induz uma interferência na cascada amiloide, impedindo sua excessiva clivagem e consequente agregação de $A \beta$.

Em estudo de Eketjäll (122) o AZD3293 foi capaz de reduzir a concentração tanto de $\mathrm{A} \beta_{40}$ quanto de $\mathrm{A} \beta_{42}$ no plasma e no LCR de camundongos, porquinhos-da-índia e cães. Segundo Eketjäll (122) os dados pré-clínicos apoiaram fortemente o desenvolvimento clínico de AZD3293; e os pacientes com DA estão atualmente sendo recrutados em um estudo combinado de Fase 2/3 para testar as propriedades modificadoras da doença de AZD3293. Em um ensaio clínico de fase I iniciado em 2013 (ClinicalTrials.gov: NCT02005211), quarenta indivíduos saudáveis foram tratados com lanabecestat e não foram observados efeitos colaterais. Dados oriundos desse ensaio clínico foram publicados e mostraram uma robusta redução na concentração de $\mathrm{A} \beta$ no sangue e no LCR dos indivíduos tratados com lanabecestat, sugerindo um potencial efeito modificador na DA (123). Em setembro de 2014, a AstraZeneca e a Eli Lilly anunciaram que desenvolveriam conjuntamente o AZD3293. Desde 2014, a Lilly ficou responsável por conduzir o desenvolvimento clínico, trabalhando com pesquisadores da Unidade de Medicamentos Inovadores da AstraZeneca para a Neurociência; a AstraZeneca, por sua vez, ficou responsável pela fabricação.

Os patrocinadores do programa de desenvolvimento clínico do composto optaram por 
propor, ao invés de uma fase II, seguida por ensaios de fase III maiores e confirmatórios, um ensaio de Fase 2/3, que chamaram de AMARANTH (ClinicalTrials.gov: NCT02245737). O ensaio clínico teve início em setembro de 2014, e a data de conclusão era marcada para agosto de 2019. O estudo pretendeu avaliar a eficácia e segurança do AZD3293, comparando-o com um placebo, a fim de desenvolver um tratamento para a DA precoce. O grupo foi constituído de 2202 pacientes entre 55 e 85 anos de ambos os gêneros. A hipótese a ser testada seria de que o AZD3293 é um tratamento modificador da doença em pessoas com DA precoce. Os participantes foram designados aleatoriamente para tomar o medicamento do estudo ou um placebo em forma de comprimido uma vez ao dia, durante dois anos. Duas doses diferentes foram testadas. Os participantes incluídos foram submetidos a uma tomografia por emissão de pósitrons (PET) ou uma punção lombar para a coleta de LCR para documentar a presença de níveis anormais de A $\beta$. Em julho de 2016, um segundo estudo de Fase III denominado DAYBREAK-ALZ (ClinicalTrials.gov: NCT02783573) foi iniciado. Este estudo envolve 1899 pacientes, de 228 localidades em todo o mundo, com demência leve devida à DA. Este ensaio tinha previsão para ser executado até 2021. No entanto, em junho de 2018, os estudos do AMARANTH e do DAYBREAK-ALZ foram suspensos devido à falta de eficácia e presença de efeitos colaterais, incluindo alta toxicidade.

\subsection{Elenbecestat (E2609, inibidor da BACE)}

O Elenbecestat (Biogen, EisaiCo.,Ltd.) é um inibidor da $\beta$-secretase (BACE). A inibição da atividade desta enzima promove a diminuição da produção de $A \beta$, o que em hipótese levaria à redução na formação de placas amiloides causadas pela agregação dos oligômeros. Com o intuito de avaliar a segurança do E2609, teve início, em dezembro de 2011, um estudo de fase I (ClinicalTrials NCT01511783) unicêntrico, randomizado, duplo-cego e controlado por placebo, envolvendo 50 indivíduos saudáveis, entre 50 e 85 anos de idade. O E2609 foi administrado por 14 dias, envolvendo as doses de 25, 50 e $200 \mathrm{mg}$, uma vez por dia, por via oral, sendo que o desfecho primário foi o aparecimento de efeitos adversos. Em maio de 2012 começou um estudo de fase I para avaliar os efeitos do E2609 (ClinicalTrials: NCT01600859). O ensaio clínico foi feito com 65 adultos, entre 50 a 85 anos, com queixas subjetivas de memória e comprometimento cognitivo leve ou demência leve devido a DA, mediante a averiguação de biomarcadores "positivos" para $A \beta$, conforme definido pelos critérios de pesquisa do Instituto Nacional do Envelhecimento - Alzheimer (NIA-AA). Os indivíduos receberam placebo ou uma dose oral única de E2609, nas concentrações de 5 $\mathrm{mg}, 10 \mathrm{mg}, 25 \mathrm{mg}, 50 \mathrm{mg}, 100 \mathrm{mg}, 200 \mathrm{mg}$ e $400 \mathrm{mg}$. Este foi um estudo randomizado, duplo-cego, controlado por placebo para avaliar a segurança, tolerabilidade, farmacocinética e farmacodinâmica de doses orais únicas de E2609, onde o desfecho primário foi a porcentagem de mudança nos níveis de A $\beta$ no LCR 36 horas após a administração do E2609.

Em outubro de 2012 começou a realização de um estudo de fase I para determinar a biodisponibilidade de comprimidos de E2609, comparados a cápsulas e o efeito dos alimentos na absorção (ClinicalTrials: NCT01716897) em 18 Adultos caucasianos de ascendência européia ou latino-americana saudáveis entre 30 e 55 anos, com índice de massa corporal (IMC) de 18 a $32 \mathrm{~kg} / \mathrm{m}^{2}$. Este foi um estudo cruzado e randomizado, com três tratamentos de doses orais únicas de uma formulação de cápsula de E2609 sob condições de jejum e uma formulação de comprimido administrada sob condições de alimentação e jejum em indivíduos saudáveis. Em 2013 foi feito um estudo de fase I, de dose única, aberto, para determinar o metabolismo e a eliminação de E2609 em 113 indivíduos saudáveis, do sexo masculino, entre 18 e 55 anos, com IMC entre 18 e 32 
$\mathrm{kg} / \mathrm{m}^{2}$ (ClinicalTrials: NCT01975636).

No início de julho de 2014, teve início um ensaio clínico de fase I para avaliar a segurança, tolerabilidade, farmacocinética e farmacodinâmica do E2609 (ClinicalTrials: NCT02207790). O ensaio clínico consistiu num estudo randomizado, duplo-cego, controlado por placebo, com dose oral única para avaliar a segurança, tolerabilidade, farmacocinética e farmacodinâmica da E2609 em indivíduos japoneses saudáveis com 32 participantes, entre 30 e 60 anos. A segurança foi avaliada por meio de monitoramento e registo de todos os eventos adversos não-graves e graves, monitoramento regular de hematologia, exames de sangue, valores de urina, medição regular de sinais vitais, eletrocardiograma e realização de exames físicos. O estudo incluiu uma coorte de indivíduos brancos tratados para comparação com a coorte de indivíduos japoneses, tratados com a mesma dose. Essa comparação serviu como uma ponte fundamental na avaliação de fatores étnicos que poderiam contribuir para diferenças nas concentrações plasmáticas.

Em agosto de 2016, teve início um estudo de fase I para avaliar a farmacocinética de E2609 e seus metabólitos em indivíduos com comprometimento hepático leve e moderado em comparação com indivíduos saudáveis (ClinicalTrials: NCT02859207). Este estudo tinha como principal objetivo avaliar os efeitos do comprometimento hepático na farmacocinética do E2609 após uma administração de dose única, na concentração de $50 \mathrm{mg}$. Ele foi composto por 32 participantes de 18 a 70 anos, com conclusão em maio de 2017.

De modo geral, até maio de 2017, seis estudos de fase I já tinham sido concluídos. De acordo com a Eisai, financiadora dos estudos, o Elenbecestat mostrou tolerabilidade aceitável em todas as doses. Os eventos adversos mais comuns foram dores de cabeça e tonturas. Nestes testes de fase I não foram observadas preocupações de segurança clinicamente significativas após doses orais repetidas de até $200 \mathrm{mg}$, e os achados de segurança no grupo de 400mg não foram divulgados.

$\mathrm{O}$ Elenbecestat tem sido desenvolvido em conjunto entre a Eisai e a Biogen. Ambas conduzem estudos clínicos de fase II e III relacionados à DA. Em novembro de 2014, um estudo clínico de fase II (ClinicalTrials: NCT02322021) de 18 meses, multicêntrico, randomizado, duplo-cego, controlado por placebo, iniciou nos Estados Unidos, em pacientes com comprometimento cognitivo leve, ou demência leve a moderada devido à DA, e com patologia amiloide confirmada por tomografia por emissão de pósitrons (PET). Setenta e um pacientes foram randomizados, recebendo 5, 15 e 50mg do fármaco ou placebo diariamente. O principal objetivo foi avaliar a segurança e tolerabilidade do Elenbecestat após 18 meses de tratamento. Os seis eventos adversos mais comuns relatados foram infecção do trato respiratório superior, sonhos e pesadelos anormais, dermatite de contato, cefaleia, diarreia e quedas. Nenhuma reação adversa sugestiva de toxicidade hepática foi observada neste estudo. Além dos objetivos de segurança, o estudo avaliou a concentração de $A \beta$ no encéfalo aos 18 meses, medido por PET, bem como a eficácia em termos de sintomas clínicos, que eram os objetivos exploratórios neste estudo. A dose de $50 \mathrm{mg}$ foi segura e gerou as maiores reduções nas concentrações de $A \beta$. Esta é a primeira vez em que um efeito significativo sobre as concentrações de $\mathrm{A} \beta$ no encéfalo, usando um inibidor da BACE, foi confirmado em um estudo clínico em pacientes com comprometimento cognitivo leve devido a DA.

Assim, a Eisai e a Biogen iniciaram dois testes de Fase III em 2016, o MISSION AD1 (ClinicalTrials: NCT02956486) e MISSION AD2 (NCT03036280). O AD1 teve início em outubro de 2016, com o objetivo de avaliar a eficácia e segurança do E2609 em sujeitos com DA inicial ou prodrômicae comprometimento cognitivo leve devido a DA (ClinicalTrials: NCT02956486), sendo um estudo multicêntrico, duplo-cego, controlado 
por placebo, com conclusão prevista para março de 2021. O estudo envolve 1330 participantes entre 50 e 85 anos, de 312 cidades (multicêntrico) e pretende comparar os efeitos do tratamento de 50mg diários com E2609 versus placebo durante dois anos. O estudo também avaliará os resultados exploratórios, como as alterações nos níveis de amiloide identificados por PET no volume do hipocampo e na conectividade funcional da ressonância magnética, além de biomarcadores do LCR.

O AD2 teve início em dezembro de 2016, com duração prevista de 24 meses. Também pretende avaliar a eficácia e segurança do E2609 em sujeitos com DA em estado inicial ou prodrômica e com comprometimento cognitivo leve devido a DA. Este está sendo realizado em 289 locais diferentes nas Américas, África do Sul, Austrália, Israel e em inúmeros países da Europa e Ásia. Sua conclusão tem previsão para 2021. Este estudo é composto, inicialmente, por 1330 sujeitos, entre 50 e 85 anos, multicêntrico, duplo-cego, controlado por placebo, onde 1330 pacientes recebem $50 \mathrm{mg}$ de Elenbecestat diariamente por dois anos. O desfecho primário é mudança na linha de base na Avaliação Clínica da Demência (CDR), além de desfechos secundários e outros desfechos que incluem: reduzir a gravidade dos sintomas de demência, reduzir os níveis de $\mathrm{A} \beta$ no encéfalo, impedir a redução do volume do hipocampo e reduzir os níveis de biomarcadores no LCR.

\subsection{Crenezumab (MABT5102A, RG7412)}

O crenezumab (AC Immune SA, Genentech, Hoffmann-La Roche) consiste em um anticorpo monoclonal (AcMos) humanizado de uma isoforma de IgG4, com alta afinidade para oligômeros e fibrilas $A \beta$, com capacidade de reduzir a agregação e promover desagregação dos agregados de $A \beta$, diminuindo a neurotoxicidade provocada pelos oligômeros, além de diminuir a ação inflamatória da micróglia (124). Cummings e colaboradores (21), avaliaram a segurança e eficácia do crenezumab em pacientes com DA leve a moderada. Neste estudo de fase II, 431 pacientes com DA leve a moderada, de 50 a 80 anos de idade, receberam crenezumab ou placebo. Os pacientes receberam baixas doses de crenezumab subcutâneo (300 mg ou placebo) a cada 2 semanas ou altas doses de crenezumab intravenoso $(15 \mathrm{mg} / \mathrm{kg}$ ou placebo) a cada 4 semanas, por 68 semanas. Os desfechos primários foram a mudança nos escores ADAS-Cog12 e Escala de CDR desde o início até a semana 73. A alta dose $(15 \mathrm{mg} / \mathrm{kg})$ apresentou potencial efeito terapêutico, embora os critérios pré-especificados para testar os efeitos do tratamento não tenham sido atendidos. Juntamente com o perfil de segurança do crenezumab, tais dados apoiam a exploração do tratamento com crenezumab em outras doses, bem como verificar sua capacidade preventiva tendo em vista avaliar quando a administração deve ser iniciada (por exemplo, em indivíduos com DA prodrômica ou portadores de modificações genéticas) (125).

Em março de 2016 e 2017 a Hoffmann-La Roche iniciou dois ensaios clínicos com ocrenezumab em fase III (ClinicalTrials.gov: NCT02670083 e NCT03114657, respectivamente). No primeiro estudo, 832 pacientes com DA prodrômica foram randomizados para receber administração endovenosa de crenezumab ou placebo mensalmente (dose não revelada), por 100 semanas, onde a avaliação sobre a eficácia da droga foi realizada após 52 semanas da última administração. O desfecho primário foi a mudança na linha de base avaliada na semana após o término do tratamento pela CDR-SB (ClinicalDementia Rating-Sum of Boxes). O estudo de 2017 possui um desenho semelhante ao estudo de 2016, no entanto é realizado com 750 pacientes. Os estudos têm previsão para término em 2021 e 2022, respectivamente. 


\section{Vittalle - Revista de Ciências da Saúde v. 31, n. 1 (2019) 84-106}

\section{Considerações finais}

Atualmente cerca de 50 milhões de pessoas são afetadas pela DA em todo o mundo (18). Tendo em vista este cenário, torna-se importante o desenvolvimento de tratamentos mais efetivos para os pacientes que sofrem com a DA. De fato, ainda há ausência de possíveis biomarcadores para esta condição neurodegenerativa, o que é um importante fator por trás das falhas em estudos clínicos, pois aumenta o risco de erros diagnósticos e corrobora para o comprometimento dos resultados nesses ensaios (21). O resultado é a condição vigente, marcada pela escassez de fármacos que possam modificar o curso da doença (i.e. neuroprotetores), como também a insistente e grave ineficácia dos fármacos já existentes. Estima-se que o número de diagnósticos incorretos em estudos clínicos pode exceder $20 \%$ (44).

O número de terapias e intervenções bem-sucedidas em modelos pré-clínicos é alto, mas quando avaliadas em ensaios clínicos com humanos o número decaí de forma quase total. Um fator importante nesse contexto é o fato de que os camundongos transgênicos da APP serem modelos da DA assintomática, isto é, os resultados dos estudos de intervenção nesses camundongos devem ser considerados no contexto da prevenção da doença, caso contrário corre-se o risco de interpretar erroneamente os resultados destes testes, consequentemente ocasionando equívocos em ensaios clínicos $(19,21)$

Vê-se, assim, que as atuais limitações ao tratamento da DA são de difícil superação, porém, ainda assim, é possível, desde que o foco atual na depuração de amiloide possa ser ampliado para incluir a manipulação de outras características patológicas, onde as intervenções sejam igualmente amplas $(21,43,126)$. A investigação clínica tradicional para uma doença como a DA é basicamente redutora; quando a causalidade de uma condição é tão mal compreendida, e os sintomas tão fracamente correlacionados a alterações fisiológicas, é improvável que tratamentos que atuem em um mecanismo de ação específico produzam resultados significativos (24). Ademais, potencialmente, a A $\beta$ pode não ser o alvo correto $(36,127)$. Embora a maioria dos esforços para desenvolver fármacos modificadoras da doença direcionadas ao $\mathrm{A} \beta$ para a DA tenham falhado, muito pode ser aprendido com esses esforços. Por exemplo, foi demonstrado que a eficácia clínica nem sempre se traduz de modelos animais para pacientes humanos. Além disso, estudos anteriores mostraram que tanto a prevenção da deposição de amiloide como a remoção de amiloide não levam, per se, a uma melhor cognição na DA, sugerindo a necessidade de entender melhor a fisiopatologia da mesma (128). Outro ponto levado em consideração são as recentes falhas de anticorpos monoclonais relacionados à hipótese amiloide, que destacam uma das mais sérias fraquezas na atual pesquisa sobre a DA: a correlação entre as alterações patológicas no encéfalo do paciente e o efeito real nas habilidades cognitivas e funcionais não ser entendida de maneira substancial. Portanto, curar uma doença cuja patologia é tão mal compreendida constitui-se como um desafio praticamente insuperável (24). Não obstante, as falhas nos estudos clínicos podem ocorrer por inúmeros fatores, como a complexidade cerebral humana, idade, variabilidade do paciente e fenótipos específicos da doença (129). No entanto, as tentativas precisam continuar, pois um atraso de um ano no início da DA, por exemplo, poderia gerar bilhões em economia nos custos médicos e de assistência (130).

No momento existem 112 novas entidades moleculares sendo testadas para DA em fases I, II e III, onde $63 \%$ são modificadoras da doença, objetivando retardar o seu princípio ou progressão; $22 \%$ visam tratar os sintomas e apenas $3 \%$ não tiveram seu mecanismo de ação revelado. Especificamente, em fase III, existem 26 agentes divididos em 3 categorias, de acordo com seus objetivos: I- 65\% são fármacos modificadores da doença, sendo que $54 \%$ destes focam na hipótese amiloide, $8 \%$ têm como alvo disfunções metabólicas e proporcionar neuroproteção, e 4\% são anti-tau. II- $31 \%$ visam o tratamento 
de sintomas neuropsiquiátricos advindos da DA, como agitação, problemas no sono ou apatia e 4\% objetivam inibir a enzima acetilcolinesterase (21). Além disso, há esforços para identificar possíveis biomarcadores que possibilitem diagnosticar a DA em fases iniciais ou assintomáticas (131-133).

Apesar das consideráveis possibilidades de fracasso e dos relevantes obstáculos a serem enfrentados (80), as promessas para o desenvolvimento de uma terapêutica efetiva para a DA são palpáveis, de modo que conhecer os principais erros translacionais na área permitiria uma progressão das taxas de sucesso no desenvolvimento de fármacos. Considera-se que os avanços efetuados nesse sentido, por meio de uma análise como a do presente trabalho, propiciam maiores esclarecimentos para futuras pesquisas e práticas na área.

\section{Conflitos de interesse}

Os autores declaram não haver conflitos de interesse.

\section{Agradecimentos}

O presente trabalho foi realizado com o apoio da Coordenação de Aperfeiçoamento de Pessoal de Nível Superior - Brasil (CAPES), a qual proporciona bolsa de mestrado aos autores Eslen, Douglas, Raul e Letícia.

\section{Referências}

1. Vigo D, Thornicroft G, Atun R. Estimating the true global burden of mental illness. Lancet Psychiatry 2016; 3(2):171-8.

2. Hyman, SE. Revolution Stalled. Science Translational Medicine. 2012; Vol. 4, Issue 155, pp. $155 \mathrm{~cm} 11$

3. Hyman, SE. Psychiatric drug development: diagnosing a crisis. Cerebrum 2013:5. Available Online at: http://www.dana.org/Cerebrum/2013/Psychiatric_Drug_Development_Diagnosing_a_Crisis/

4. Mullard A. 2010 FDA drug approvals. Nature Reviews Drug Discovery. 2011; vol 10, pages 82-85

5. Mullard A. 2011 FDA drug approvals. Nature Reviews Drug Discovery. 2012; vol 11, pages 91-94.

6. Mullard A. 2012 FDA drug approvals. Nature Reviews Drug Discovery. 2013; vol 12, pages 87-90.

7. Mullard A. 2013 FDA drug approvals. Nature Reviews Drug Discovery. 2014; vol 13, pages 85-9.

8. Mullard A. 2014 FDA drug approvals. Nature Reviews Drug Discovery. 2015; vol 14, pages 77-81.

9. Mullard A. 2015 FDA drug approvals. Nature Reviews Drug Discovery. 2016; vol 15, pages 73-76.

10. Mullard A. 2016 FDA drug approvals. Nature Reviews Drug Discovery. 2017; vol 16, pages 73-76.

11. Mullard A. 2017 FDA drug approvals. Nature Reviews Drug Discovery. 2018; vol 17, pages 81-85.

12. Nutt D, Goodwin G. ECNP Summit on the future of CNS drug research in Europe 2011: report prepared for ECNP by David Nutt and Guy Goodwin. Eur Neuropsychopharmacol 2011; 21(7):495-9.

13. Phillips AG, Hongaard-Andersen P, Moscicki RA, Sahakian B, Quirion R, Krishnan KR, et al. Proceedings of the 2013 CINP summit: innovative partnerships to accelerate CNS drug discovery for improved patient care. The international journal of neuropsychopharmacology 2015; 18(3), pyu100.

14. Abbott, A. Dementia. A problem for our age. Nature 2011; 475, S2-S4.

15. Mullard A. Pfizer exits neuroscience. Nature Reviews Drug Discovery 2018; 17: 86.

16. Pankevich DE, Altevogt BM, Dunlop J, Gage FH, Hyman SE. Improving and Accelerating Drug Development for Nervous System Disorders 2014; 84 (3): 546-553.

17. Silber BM. Driving drug discovery: the fundamental role of academic labs. Sci Transl Med 2010; 5;2(30):30 $\mathrm{cm} 16$.

18. Prince M, Comas-Herrera A, Knapp, M, Guerchet M, Karagiannidou M. World Alzheimer report 2016: improving healthcare for people living with dementia: coverage, quality and costs now and in 


\section{Vittalle - Revista de Ciências da Saúde v. 31, n. 1 (2019) 84-106}

the future. Alzheimer's Disease International (ADI) 2016; London, UK.

19. LaFerla FM, Green KN. Animal Models of Alzheimer Disease. Cold Spring Harbor Perspectives in Medicine 2012; 2(11), a006320.

20. Hyde C, Peters J, Bond M, Rogers G, Hoyle M, Anderson R, et al. Evolution of the evidence on the effectiveness and cost-effectiveness of acetylcholinesterase inhibitors and memantine for Alzheimer's disease: systematic review and economic model. Age and Ageing 2013; 42: 14-20

21. Cummings JL, Cohen S, van Dyck CH, Brody M, Curtis C, Cho W, et al. A phase 2 randomized trial of crenezumab in mild to moderate Alzheimer disease. Neurology 2018; 90(21): e1889-e1897.

22. Lukiw WJ. NF-кB-regulated, proinflammatorymiRNAs in Alzheimer's disease. Alzheimers Res Ther 2012; 4(6): 47.

23. Karran E, Hardy J. A Critique of the Drug Discovery and Phase 3 Clinical Programs Targeting the Amyloid Hypothesis for Alzheimer Disease. Annals of Neurology 2014; 76(2), 185-205.

24. Berk C, Paul G, Sabbagh M. Investigational drugs in Alzheimer's disease: current progress. Expert Opin Investig Drugs 2014; 23(6):837-46.

25. Mangialasche F, Solomon A, Winblad B, Mecocci P, Kivipelto M. Alzheimer's disease: clinical trials and drug development. Lancet Neurol 2010; 9(7):702-16.

26. Forum on Neuroscience and Nervous System Disorders; Board on Health Sciences Policy; Institute of Medicine. Improving and Accelerating Therapeutic Development for Nervous System Disorders: Workshop Summary. The National Academies Collection: Reports funded by National Institutes of Health. Washington (DC): National Academies Press (US); 2014.

27. Hughes JP, Rees S, Kalindjian SB, Philpott KL. Principles of early drug discovery. Br J Pharmacol 2011; 162(6):1239-49.

28. Cook D, Brown D, Alexander R, March R, Morgan P, Satterthwaite G, Pangalos MN. Lessons learned from the fate of AstraZeneca's drug pipeline: a five-dimensional framework. Nature Reviews Drug Discovery 2014; 13: 419-431.

29. Hardy JA, Higgins GA. Alzheimer's disease: the amyloid cascade hypothesis. Science 1992; 10;256(5054):184-5.

30. Haass C, Selkoe DJ. Soluble protein oligomers in neurodegeneration: lessons from the Alzheimer's amyloid beta-peptide. Nat Rev Mol Cell Biol 2007;8(2):101-12.

31. Ferreira ST, Klein WL. The A $\beta$ oligomer hypothesis for synapse failure and memory loss in Alzheimer's disease. Neurobiol Learn Mem 2011;96(4):529-43.

32. Citron M. $\beta$-secretase as a target for the treatment of Alzheimer's disease. J Neurosci Res 2002; 70 (3): 373-379.

33. Selkoe DJ. Alzheimer's disease: genes, proteins, and therapy. Physiol Rev 2001;81(2):741-66.

34. Hardy J, Selkoe DJ. The amyloid hypothesis of Alzheimer's disease: progress and problems on the road to therapeutics. Science 2002;297(5580):353-6.

35. Chow VW, Savonenko AV, Melnikova T, Kim H, Price DL, Li T, et al. Modeling an Anti-Amyloid Combination Therapy for Alzheimer's Disease. Sci Transl Med 2010 ; 2(13): 13ra1.

36. Querfurth HW, LaFerla FM. Alzheimer's disease. N Engl J Med 2010;362(4):329-44.

37. Kurz A, Perneczky R. Amyloid clearance as a treatment target against Alzheimer's disease.JAlzheimers Dis 2011;24 Suppl 2:61-73.

38. Mandrekar-Colucci S, Landreth GE. Microglia and inflammation in Alzheimer's disease. CNS NeurolDisord Drug Targets 2010;9(2):156-67.

39. Wilcox KC, Lacor PN, Pitt J, Klein WL. A $\beta$ oligomer-induced synapse degeneration in Alzheimer's disease.CellMolNeurobiol2011;31(6):939-48.

40. Akiyama H, Barger S, Barnum S, Bradt B, Bauer J, Cole GM, et al. Inflammation and Alzheimer's disease. Neurobiol Aging 2000;21(3):383-421.

41. Schneider LS, Mangialasche F, Andreasen N, Feldman H, Giacobini E, Jones R, et al. Clinical trials and late-stage drug development for Alzheimer's disease: an appraisal from 1984 to 2014. J Intern Med 2014; 275(3):251-83.

42. Aisen PS, Vellas B, Hampel H. Moving towards early clinical trials for amyloid-targeted therapy in Alzheimer's disease. Nature Rev Drug Discov 2013; 12:324. 
43. Godyń J, Jończyk J, Panek D, Malawska B. Therapeutic strategies for Alzheimer's disease in clinical trials. Pharmacol Rep 2016; 68(1):127-38.

44. Doody RS, Farlow M, Aisen PS. Alzheimer's Disease Cooperative Study Data A, Publication C. Phase 3 trials of solanezumab and bapineuzumab for Alzheimer's disease. N Engl J Med 2014; 370:1460.

45. Salloway S, Sperling R, Fox NC, Blennow K, Klunk W, Raskind M, et al. Two Phase 3 Trials of Bapineuzumab in Mild-to-Moderate Alzheimer's Disease. The New England Journal of Medicine 2014;370(4), 322-333.

46. Honig LS, Vellas B, Woodward M, Boada M, Bullock R, Borrie M, et al. Trial of Solanezumab for Mild Dementia Due to Alzheimer's Disease. N Engl J Med 2018; 378:321-330.

47. Doody RS, Raman R, Farlow M, Iwatsubo T, Vellas B, Joffe S, et al. Alzheimer's Disease Cooperative Study Steering Committee, Siemers E, Sethuraman G, Mohs R; Semagacestat Study Group. A phase 3 trial of semagacestat for treatment of Alzheimer's disease. N Engl J Med 2013; 369(4):341-50.

48. Green RC, Schneider LS, Amato DA, Beelen AP, Wilcock G, Swabb EA, et al. Tarenflurbil Phase 3 Study Group. Effect of tarenflurbil on cognitive decline and activities of daily living in patients with mild Alzheimer disease: a randomized controlled trial. JAMA 2009; 302(23):2557-64.

49. Xia W, Wong ST, Hanlon E, Morin P. $\gamma$-Secretase modulator in Alzheimer's disease: shifting the end. J Alzheimers Dis 2012; 31(4):685-96.

50. Aisen PS, Gauthier S, Ferris SH, Saumier D, Haine D, Garceau D, et al. Tramiprosate in mild-tomoderate Alzheimer's disease - a randomized, double-blind, placebo-controlled, multi-centre study (the Alphase Study). Arch Med Sci 2011;7(1):102-11.

51. Yan R, Vassar R. Targeting the $\beta$ secretase BACE1 for Alzheimer's disease therapy. Lancet Neurol 2014; 13(3):319-29.

52. Forman M, Palcza J, Tseng J, Leempoels J, Ramael S, Han D, et al.. The novel BACE inhibitor MK8931 dramatically lowers cerebrospinal fluid A $\beta$ peptides in healthy subjects following single- and multiple-dose administration. Alzheimers Dement 2012; 8:P704.

53. Forman M, Kleijn HJ, Dockendorf M, Palcza J, Tseng J, Canales C, et al. The novel BACE inhibitor MK-8931 dramatically lowers CSF beta-amyloid in patients with mild-to-moderate Alzheimer's disease. Alzheimers Dement 2013;9:P139.

54. Egan MF, Kost J, Tariot PN, Aisen PS, Cummings JL, Vellas B, et al. Randomized Trial of Verubecestat for Mild-to-Moderate Alzheimer's Disease. N Engl J Med 2018; 378:1691-1703.

55. Giacobini E, Gold G. Alzheimer disease therapy--moving from amyloid- $\beta$ to tau. Nat Rev Neurol 2013; 9(12):677-86.

56. Pimplikar SW. Reassessing the amyloid cascade hypothesis of Alzheimer's disease. Int J Biochem Cell Biol 2009; 41(6):1261-8.

57. Morris JC, Blennow K, Froelich L, Nordberg A, Soininen H, Waldemar G, et al. Harmonized diagnostic criteria for Alzheimer's disease: recommendations. J Intern Med. 2014; 275(3):204-13.

58. Kola I, Landis J. Can the pharmaceutical industry reduce attrition rates? Nat Rev Drug Discov2004; 3(8):711-5.

59. Markou A, Chiamulera C, Geyer MA, Tricklebank M, Steckler T. Removing obstacles in neuroscience drug discovery: The future path for animal models. Neuropsychopharmacology 2009; 34(1), 74-89.

60. Kola I. The State of Innovation in Drug Development. Innovations in Drug Development 2008; 83 (2): $227-230$.

61. Wang D, Yuen EY, Zhou Y, Yan Z, Xiang YK. Amyloid beta peptide-(1-42) induces internalization and degradation of beta2 adrenergic receptors in prefrontal cortical neurons. J Biol Chem 2011; 286 31852-31863

62. Van Dam D, De Deyn PP. Animal models in the drug discovery pipeline for Alzheimer's disease. $\mathrm{Br}$ J Pharmacol 2011;164(4):1285-300.

63. McGonigle P. Animal models of CNS disorders. Biochem Pharmacol 2014; 87:140-149

64. Cummings JL. Frontal-subcortical ciruits and human behavior. Archives of Neurology 1993; 50, 873-880.

65. Rofina JE, van EderenAM, Toussaint MJ, Secrève M, van der Spek A, van der Meer I, Van Eerdenburg FJ, Gruys E. Cognitive disturbances in old dogs suffering from the canine counterpart of Alzheimer's disease. Brain Res 2006; 1069(1):216-26. 


\section{Vittalle - Revista de Ciências da Saúde v. 31, n. 1 (2019) 84-106}

66. Head E, Moffat K, Das P, Sarsoza F, Poon WW, Landsberg G, et al. Beta-amyloid deposition and tau phosphorylation in clinically characterized aged cats. Neurobiol Aging 2005; 26(5):749-63

67. Cork LC, Powers RE, Selkoe DJ, Davies P, Geyer JJ, Price DL. Neurofibrillary tanglesand senile plaques in aged bears. J NeuropatholExpNeurol1988; 47:629-641.

68. Uchida K, Yoshino T, Yamaguchi R, Tateyama S, Kimoto Y, Nakayama H, et al. Senile plaques and other senile changes in the brain of an aged American black bear. Vet Pathol 1995; 32(4):412-4.

69. Braak H, Braak E, Strothjohann M. Abnormally phosphorylated tau protein related to the formation of neurofibrillary tangles and neuropil threads in the cerebral cortex of sheep and goat. Neurosci Lett 1994;171(1-2):1-4.

70. Geula C, Nagykery N, Wu CK. Amyloid-beta deposits in the cerebral cortex of the aged common marmoset (Callithrixjacchus): incidence and chemical composition. Acta Neuropathol 2002;103(1):48-58.

71. Sani S, Traul D, Klink A, Niaraki N, Gonzalo-Ruiz A, Wu CK, et al. Distribution, progression and chemical composition of cortical amyloid-beta deposits in aged rhesus monkeys: similarities to the human. Acta Neuropathol 2003 ;105(2):145-56.

72. Lemere CA, Oh J, Stanish HA, Peng Y, Pepivani I, Fagan AM, et al. Cerebral amyloid-beta protein accumulation with aging in cotton-top tamarins: a model of early Alzheimer's disease? Rejuvenation Res 2008;11(2):321-32.

73. Van Dam D, De Deyn PP. Drug discovery in dementia: the role of rodent models. Nat Rev Drug Discov 2006;5(11):956-70.

74. Sherman KA, Friedman E. Pre and post-synapptic cholinergic dysfunction in aged rodent brain regions: new findings and an interpretative review. Int J De Neurosci 1990; 8: 689-708.

75. Erickson CA, Barnes CA. The neurobiology of memory changes in normal aging. Exp Gerontol 2003;38(1-2):61-9.

76. Corder EH, Saunders AM, Strittmatter WJ, Schmechel DE, Gaskell PC, Small GW, et al. Gene dose of apolipoprotein $\mathrm{E}$ type 4 allele and the risk of Alzheimer's disease in late onset families.Science.1993;261(5123):921-3.

77. Strittmatter WJ, Saunders AM, Schmechel D, Pericak-Vance M, Enghild J, Salvesen GS, et al.Apolipoprotein E: high-avidity binding to beta-amyloid and increased frequency of type 4 allele in late-onset familial Alzheimer disease. Proc Natl Acad Sci U S A. 1993; 90(5):1977-81.

78. Lee J-E, Han P-L. An Update of Animal Models of Alzheimer Disease with a Reevaluation of Plaque Depositions. Exp Neurobiol 2013; 22(2): 84-95.

79. Onos KD, Sukoff Rizzo SJ, Howell GR, Sasner M. Toward more predictive genetic mouse models of Alzheimer's disease. Brain Res Bull 2016;122:1-11.

80. Selkoe DJ. Resolving controversies on the path to Alzheimer's therapeutics. Nat Med 2011; 17(9):1060-5.

81. Herrup K, Carrillo M, Schenk D, Cacace A, DeSanti S, Fremeau R, et al. Beyond Amyloid: Getting Real about Non-Amyloid Targets in Alzheimer's Disease. Alzheimers Dement 2013; 9(4): 452-458.

82. Boggs LN, Fuson KS, Gitter BD, Czilli DL, Hyslop PA, Bender MH, et al.In vivo characterization of LY450139, a novel, stereoselective, functional $\gamma$-secretase inhibitor.Neurobiol Aging 2004; 25 (2): P1-419

83. May PC, Yang Z, Li WY, Hyslop PA, Siemers E, Boggs LN. Multi-compartmental pharmacodynamic assessment of the functional $\gamma$-secretase inhibitor LY450139 in PDAPP transgenic mice and non-transgenic mice. Neurobiol Aging 2004; 25 (2): O3-06-07.

84. Ness DK, Boggs LN, Hepburn DL, Gitter B, Long GG, May PC, et al. Reduced $\beta$-amyloid burden, increased C-99 concentrations and evaluation of neuropathology in the brains of PDAPP mice given LY450139 dihydrate daily by gavage for 5 months. Neurobiol Aging 2004; 25 (2): P2-053.

85. Fleisher AS, Raman R, Siemers ER, Becerra L, Clark CM, Dean RA, et al. Phase 2 safety trial targeting amyloid beta production with a gamma-secretase inhibitor in Alzheimer disease. Arch Neurol 2008; 65(8): 1031-8.

86. Siemers ER, Quinn JF, Kaye J, Farlow MR, Porsteinsson A, Tariot P, et al. Effects of a gammasecretaseinhibitor in a randomized study of patients with Alzheimer disease. Neurology 2006; 66(4): 602-4.

87. Siemers ER, Dean RA, Friedrich S, Ferguson-Sells L, Gonzales C, Farlow MR, et al. Safety, tolerability, and effects on plasma and cerebrospinal fluid amyloid-beta after inhibition of gammasecretase. Clin Neuropharmacol 2007; 30(6):317-25. 
88. Abramowski D, Wiederhold KH, Furrer U, Jaton AL, Neuenschwander A, Runser MJ, et al. Dynamics of Abeta turnover and deposition in different beta-amyloid precursor protein transgenic mouse models following gamma-secretase inhibition. J Pharmacol Exp Ther 2008;327(2):411-24.

89. Henley DB, Sundell KL, Sethuraman G, Dowsett SA, May PC. Safety profile of semagacestat, a gamma-secretase inhibitor: Identity trial findings. Curr Med Res Opin 2014; 30(10):2021-32.

90. De Strooper B. Lessons from a failed $\gamma$-secretase Alzheimer trial. Cell 2014; 159(4):721-6.

91. Bateman RJ, Siemers ER, Mawuenyega KG, Wen G, Browning KR, Sigurdson WC, et al.A gammasecretase inhibitor decreases amyloid-beta production in the central nervous system. Ann Neurol 2009; 66(1):48-54.

92. Lanz TA, Karmilowicz MJ, Wood KM, Pozdnyakov N, Du P, Piotrowski MA, et al. Concentrationdependent modulation of amyloid-beta in vivo and in vitro using the gamma-secretase inhibitor, LY450139. J Pharmacol Exp Ther 2006; 319(2):924-33.

93. Johnson-Wood K, Lee M, Motter R, Hu K, Gordon G, Barbour R, Khan K, Gordon M, Tan H, Games D, Lieberburg I, Schenk D, Seubert P, McConlogue L. Amyloid precursor protein processing and A beta42 deposition in a transgenic mouse model of Alzheimer disease. Proc Natl Acad Sci U S A 1997; 94(4):1550-5.

94. Miles LA, Crespi GAN, Doughty L, Parker MW. Bapineuzumab captures the N-terminus of the Alzheimer's disease amyloid-beta peptide in a helical conformation. Scientific reports 2013;3:1302.

95. Bard F, Cannon C, Barbour R, Burke RL, Games D, Grajeda H, et al. Peripherally administered antibodies against amyloid betapeptide enter the central nervous system and reduce pathology in a mouse model of Alzheimer disease. Nat Med 2000;6(8):916-9.

96. Zago W, Buttini M, Comery TA, Nishioka C, Gardai SJ, Seubert P, et al. Neutralization of soluble, synaptotoxic amyloid beta species by antibodies is epitope specific. J Neurosci 2012;32(8):2696-702.

97. Schenk D, Barbour R, Dunn W, Gordon G, Grajeda H, Guido T, et al. Immunization with amyloid-beta attenuates Alzheimer-disease-like pathology in the PDAPP mouse. Nature 1999; 400(6740):173-7.

98. Seubert P, Barbour R, Khan K. Antibody capture of soluble Abeta does not reduce cortical A beta amyloidosis in the PDA $\beta$ PP mouse. Neurodegener Dis 2008; 5:65-71.

99. Vandenberghe R, Rinne JO, Boada M, Katayama S, Scheltens P, Vellas B, et al.. Bapineuzumab for mild to moderate Alzheimer's disease in two global, randomized, phase 3 trials. Alzheimers Res Ther 2016; 8(1):18.

100. Seubert P, Vigo-Pelfrey C, Esch F, Lee M, Dovey H, Davis D, et al. Isolation and quantification of soluble Alzheimer's $\beta$-peptide from biological fluids. Nature 1992; 359:325-27.

101. Selkoe DJ. Amyloid $\beta$-protein and the genetics of Alzheimer's disease.J BiolChem1996;271:18295-98.

102. Mably AJ, Liu W, Mc Donald JM, Dodart J-C, Bard F, Lemere CA, et al. Anti-A $\beta$ antibodies incapable of reducing cerebral $A \beta$ oligomers fail to attenuate spatial reference memory deficits in J20 mice. Neurobiology of Disease 2015; 82, 372-384.

103. DeMattos RB; Bales KR; Cummins DJ; Dodart JC; Paul SM; Holtzman DM. Peripheral anti-A $\beta$ antibody alters CNS and plasma $A \beta$ clearance and decreases brain $A \beta$ burden in a mouse model of Alzheimer's disease. ProcNatlAcadSci USA 2001; 98, 8850-8855.

104. Siemers ER, Sundell KL, Carlson C, Case M, Sethuraman G, Liu-Seifert H, et al. Phase 3 solanezumab trials: Secondary outcomes in mild Alzheimer's disease patients. Alzheimers Dement. 2016; 12(2):110-120.

105. Bussiere T, Weinreb PH, Dunstan RW, Qian F, Arast MF, Li M, et al. Differential in vitro and in vivo binding profiles of BIIB037 and other anti-abeta clinical antibody candidates. Neurodegener Dis 2013; 11(Suppl 1).

106. Ferrero J, Williams L, Stella H, Leitermann K, Mikulskis A, O'Gorman J, et al.First-in-human, double-blind, placebo-controlled, single-dose escalation study ofaducanumab (BIIB037) in mild-tomoderate Alzheimer's disease. Alzheimer's Dement Translat Res Clin Interv 2016;2:169e76.

107. Sevigny J, Chiao P, Bussière T, Weinreb PH, Williams L, Maier M, et al.. The antibody aducanumabreduces $A \beta$ plaques in Alzheimer's disease. Nature 2016; 537(7618):50-56.

108. Barsuhn CL, Olanoff LS, Gleason DD, Adkins EL, Ho NF. Human buccal absorption of flurbiprofen. Clinical pharmacology and therapeutics 1988; 44: 225-231.

109. Gonzalez-Younes I, Wagner JG, Gaines DA, Ferry JJ, Hageman JM. Absorption of flurbiprofen 


\section{Vittalle - Revista de Ciências da Saúde v. 31, n. 1 (2019) 84-106}

through human buccal mucosa. Journal of Pharmaceutical Sciences 1991; 80, 820-823.

110. Wyss-Coray T, Rogers J. Inflammation in Alzheimer Disease - A Brief Review of the Basic Science and Clinical Literature. Cold Spring Harbor Perspectives in Medicine 2012; 2(1), a006346.

111. Hawkeu CJ. COX-2 Inhibitors. Nature.1999; 353:307-314

112. Hull M, Lieb K, Fiebich BL. Anti-inflammatory drugs: a hope for Alzheimer's disease? Expert OpinInvestig Drugs 2000; 9: 671-683.

113. McGeer PL, Schulzer M, McGeer EG. Arthritis and anti-inflammatory agents as possible protective factors for Alzheimer's disease: a review of 17 epidemiologic studies. Neurology 1996; 47:425-432

114. Eriksen JL, Sagi SA, Smith TE, Weggen S, Das P, McLendon DC, et al. NSAIDs and enantiomers of flurbiprofen target gamma-secretase and lower A $\beta 42$ in vivo. J Clin Invest 2003; 112(3): 440-449.

115. Kukar T, Prescott S, Eriksen JL, Holloway V, Murphy MP, Koo EH, et al. Chronic administration of R-flurbiprofen attenuates learning impairments in transgenic amyloid precursor protein mice. BMC Neuroscience 2007; 8:54;

116. Weggen S, Eriksen JL, Das P. A subset of NSAIDs lower amyloidogenic A $\beta 42$ independently of cyclooxygenase activity. Nature 2001;414:212-216.

117. Wilcock GK. Efficacy and safety of tarenflurbil in mild to moderate Alzheimer's disease: a randomised phase II trial. Lancet Neurol 2008;7(6):483-93.

118. Wilcock GK, Black SE, Balch AH, Amato DA, Beelen AP, Schneider LS, et al. Safety and efficacy of tarenflurbil in subjects with mild Alzheimer's disease: results from an 18-month international multi-center Phase 3 trial. Alzheimers Dement 2009; 5(1): P86 (Abstract O1-04-07).

119. Aisen PS. Tarenflurbil: a shot on goal. Lancet Neurol 2008;7(6):468-9.

120: Genetics M. Myriad Genetics Reports Results of U.S. Phase 3 Trial of Flurizan in Alzheimer's Disease- Flurizan Fails to Achieve Significance on Either CoPrimary Endpoint; Company Has Decided to Discontinue Its Development of Flurizan. 2008. Disponível em: www.myriad.com.

121. Vellas B. Tarenflurbil for Alzheimer's disease: a "shot on goal" that missed. The Lancet Neurology 2010; 9(3): 235-237.

122. Eketjäll S, Janson J, Kaspersson K, Bogstedt A, Jeppsson F, Fälting J, et al. AZD3293: A Novel, Orally Active BACE1 Inhibitor with High Potency and Permeability and Markedly Slow Off-Rate Kinetics. J Alzheimers Dis 2016; 50: 1109-1123.

123. Sakamoto K, Matsuki S, Matsuguma K, Yoshihara T, Uchida N, Azuma F, et al. BACE1 Inhibitor Lanabecestat (AZD3293) in a Phase 1 Study of Healthy Japanese Subjects: Pharmacokinetics and Effects on Plasma and Cerebrospinal Fluid A $\beta$ Peptides. J ClinPharmacol 2017;57(11):1460-1471

124. Ultsch M, Li B, Maurer T, Mathieu M, Adolfsson O, Muhs A, et al. Structure of Crenezumab Complex with A $\beta$ Shows Loss of $\beta$-Hairpin. Scientific Reports 2016; 6, 39374.

125. Rygiel K Novel strategies for Alzheimer's disease treatment: An overview of anti-amyloid beta monoclonal antibodies. Indian Journal of Pharmacology 2016; 48(6), 629-636.

126. Swerdlow RH. Pathogenesis of Alzheimer's disease. Clinical Interventions in Aging 2007; 2(3), 347-359.

127. Berk C, Sabbagh MN. Successes and failures for drugs in late-stage development for Alzheimer's disease.Drugs Aging. 2013;30(10):783-92.

128. Golde TE, Schneider LS, Koo, EH. Anti-A $\beta$ therapeutics in Alzheimer's disease: The Need for a Paradigm Shift. Neuron 2011;69(2), 203-213.

129. Dragunow M. The adult human brain in preclinical drug development. Nat Rev Drug Disco 2008; 7(8):659-66.

130. Zissimopoulos J, Crimmins E, St Clair P. The value of delaying Alzheimer's disease onset. Forum Health Econ Policy 2014; 18:25-39.

131. Tijms BM, Vermunt L, Zwan MD, van Harten AC, van der Flier WM, Teunissen CE, et al.. Preamyloid stage of Alzheimer's disease in cognitively normal individuals. Ann Clin Transl Neurol 2018; 5(9):1037-1047.

132. Leuzy A, Heurling K, Ashton NJ, Schöll M, Zimmer ER. In vivo Detection of Alzheimer's Disease. The Yale Journal of Biology and Medicine 2018; 91(3), 291-300.

133. Tan C-C, Yu J-T, Tan L. Biomarkers for Preclinical Alzheimer's Disease. Journal of Alzheimer's Disease 2014; 42(4), 1051-1069. 
E. Delanogare et al/ Vittalle v. 31, n. 1 (2019) 84-106

\author{
EDITORA E GRÁFICA DA FURG \\ CAMPUS CARREIROS \\ CEP 96203900 \\ editora@furg.br
}

